\title{
WHAT'S NEW IN THE NETWORK NEUTRALITY DEBATE
}

\author{
Rob Frieden*
}

2015 MiCH. ST. L. REV. 739

TABLE OF CONTENTS

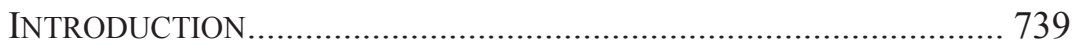

I. Converging Technologies And Markets AdD NeW

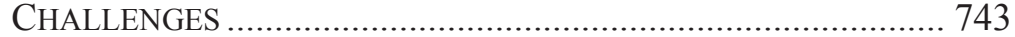

A. Ex Ante Versus Ex Post Safeguards ................................. 745

B. Can the Internet Ecosystem Self-Regulate? .................... 746

1. CDN-Retail ISP Conflicts.......................................... 754

2. Recurring Litigation and Uncertainty ........................ 757

II. CURRENT STRESS POINTS AND DISPUTES................................ 764

A. Internet Protocol Television and OTT Applications Trigger Vast Increases in Downstream Traffic .............. 766

B. Increasing Content and Delivery Costs Result in More Interconnection and Compensation Disputes and Creative Solutions ................................................... 768

C. Scope and Timetable for FCC Remedies Under $\S 706$ of the Communications Act............................................. 771

D. New Disruptors ........................................................... 775

1. Aereo and Questions About Cloud-Based Content Access ................................................................ 776

2. Other Types of Disintermediation .............................. 783

III. IS THERE A WAY FORWARD? ................................................. 785

\section{INTRODUCTION}

For over ten years, academics, ${ }^{1}$ policy makers, ${ }^{2}$ and other stakeholders $^{3}$ have debated whether and how governments should

* Pioneers Chair and Professor of Telecommunications and Law, Penn State University, 102 Carnegie Building, University Park, Pennsylvania 16802; (814) 863-7996; rmf5@psu.edu; website: http://www.personal.psu.edu/faculty/r/ $\mathrm{m} / \mathrm{rmf} 5 /$.

1. See, e.g., Ivar A. Hartmann, A Right to Free Internet? On Internet Access and Social Rights, 13 J. High TECH. L. 297 (2013); Lixian Hantover, Comment, Creating Sustainable Regulation of the Open Internet, 20 UCLA ENT. L. Rev. 107 (2013); Amanda Leese, Note, Net Transparency: Post-Comcast FCC 
regulate the Internet with an eye toward promoting accessibility, affordability, and neutrality. ${ }^{4}$ This issue has triggered grave concerns

Authority to Enforce Disclosure Requirements Critical to "Preserving the Open Internet," 11 Nw. J. Tech. \& Intell. Prop. 81 (2013); Daniel A. Lyons, Net Neutrality and Nondiscrimination Norms in Telecommunications, 54 ARIZ. L. REV. 1029 (2012); Adam Candeub \& Daniel McCartney, Law and the Open Internet, 64 FeD. Comm. L.J. 493 (2012); Rob Frieden, Rationales for and Against Regulatory Involvement in Resolving Internet Interconnection Disputes, 14 YALE J.L. \& TECH. 266 (2012); Dirk Grunwald, The Internet Ecosystem: The Potential for Discrimination, 63 FeD. Comm. L.J. 411 (2011); Rob Frieden, Assessing the Merits of Network Neutrality Obligations at Low, Medium and High Network Layers, 115 Penn St. L. Rev. 49 (2010); Marvin Ammori, Beyond Content Neutrality: Understanding Content-Based Promotion of Democratic Speech, 61 FeD. Comm. L.J. 273 (2009); Sascha D. Meinrath \& Victor W. Pickard, Transcending Net Neutrality: Ten Steps Toward an Open Internet, 12 J. InTERNET L., Dec. 2008, at 1; Tim Wu \& Christopher S. Yoo, Keeping the Internet Neutral?: Tim Wu and Christopher Yoo Debate, 59 FeD. Comm. L.J. 575 (2007); Christopher S. Yoo, Would Mandating Broadband Network Neutrality Help or Hurt Competition? A Comment on the End-To-End Debate, 3 J. on Telecomm. \& High Tech. L. 23 (2004); Tim Wu, Network Neutrality, Broadband Discrimination, 2 J. ON TELECOMM. \& High TECH. L. 141 (2003).

2. See, e.g., Statement by FCC Chairman Tom Wheeler on the FCC's Open Internet Rules (Feb. 19, 2014), available at http://www.fcc.gov/document/ statement-fcc-chairman-tom-wheeler-fccs-open-internet-rules; see also Grant Gross, Bill Would Prohibit FCC from Reclassifying Broadband as Utility, PCWORLD (May 29, 2014, 2:17 PM), http://www.pcworld.com/article/2303080/bill-would-prohibitfcc-from-reclassifying-broadband-as-utility.html.

3. Free Press, Net Neutrality, SAVE INTERNET, http://www.savetheinternet. com/net-neutrality (last visited Apr. 15, 2015); Home, NetCompetition, http://www.netcompetition.org/ (last visited Apr. 15, 2015); Network Neutrality, PuB. KNOwLEDGE, https://www.publicknowledge.org/issues/net-neutrality (last visited Apr. 15, 2015); Protect the Free-Market Internet, Am. Commitment (Feb. 26, 2015), http://www.americancommitment.org/issues/protect-free-market-internet.

4. Network neutrality refers to government-mandated nondiscrimination, transparency, and other requirements on ISPs designed to foster a level competitive playing field among content providers and to establish consumer safeguards so that Internet users have unrestricted access limited only by legitimate concerns such as ISP network management and national security. See Preserving the Open Internet, 25 FCC Rcd. 17,905, 17,933 (2010), aff'd in part, vacated and remanded in part sub nom. Verizon v. FCC, 740 F.3d 623 (D.C. Cir. 2014), on remand Protecting and Promoting the Open Internet, 79 Fed. Reg. 37,448 (Jul. 1, 2014).

For background on network neutrality initiatives outside the United States, see, e.g., Report on the Proposal for a Regulation of the European Parliament and of the Council Laying Down Measures Concerning the European Single Market for Electronic Communications and to Achieve a Connected Continent, and Amending Directives 2002/20/EC, 2002/21/EC, 2002/22/EC, and Regulations (EC) No 1211/2009 and (EU) No 531/2012, Eur. PARLIAMENT (Mar. 20, 2014), http://www.europarl.europa.eu/sides/getDoc.do?pubRef=-//EP//TEXT+ $\mathrm{PV}+20140403+\mathrm{ITEM}-007-05+\mathrm{DOC}+\mathrm{XML}+\mathrm{V} 0 / / \mathrm{EN}$; Digital Agenda for Europe: $A$ 
about the Internet's ability to continue generating substantial and widespread benefits. Advocates for various outcomes have vastly different assessments about many baseline subjects, including the likelihood that Internet Service Providers (ISPs) can self-regulate in a robustly competitive marketplace. Consumers become confused by different framing of the issues, particularly when participants in the Internet ecosystem cannot reach closure on interconnection and compensation issues. Increasingly, these disputes result in temporary blockage of specific sources and types of content, or general service degradation. ${ }^{5}$

Advocates for government oversight have not produced a large and compelling empirical record of long-term harm, ${ }^{6}$ instead relying on forecasts that biased networks will reduce the future value, accessibility, and utility of the Internet. Opponents argue that regulatory intervention to solve unproven harms imposes costs, including uncertainty about the scope of government regulation and a net reduction in innovation and investment in Internet infrastructure

Europe 2020 Initiative, EuR. COMMISSION, https://ec.europa.eu/digital-agenda/en/euactions (last updated Feb. 3, 2015); Catherine Jasserand, Critical Views on the French Approach to "Net Neutrality," 16 J. InTERnET L., Mar. 2013, at 18; European Parliament, Directorate-General for Internal Policies, Network Neutrality: Challenges AND Responses in the EU AND IN the U.S. 13 (2011), available at http://www.europarl.europa.eu/document/activities/cont/201108/ 20110825ATT25266/20110825ATT25266EN.pdf; Toshiya Jitsuzumi, Discussion on Network Neutrality: Japan's Perspective, 3 Comm. \& Convergence ReV. 71 (2011).

5. In 2008, Sprint and Cogent "de-peered" their networks, causing temporary service disruptions between their customers. See Om Malik, Cogent, Sprint Disconnect Networks, May Cause Web Slowdown, GigaOM (Oct. 30, 2008, 10:50 PM), http://gigaom.com/2008/10/30/cogent-sprint-un-peer-may-cause-webslowdown. In early 2014, Netflix subscribers complained about degraded network performance that significantly affected their viewing experience. See Drew Fitzgerald \& Shalini Ramachandran, Netflix-Traffic Feud Leads to Video Slowdown, WALL ST. J. (Feb. 18, 2014, 9:35 PM), http:/online.wsj.com/news/articles/ SB10001424052702304899704579391223249896550; Randell Suba, NetflixVerizon Standoff: Only Net Neutrality Can Now Stop Video Slowdown, TECH TimeS (Feb. 23， 2014， 7:27 AM), http:/www.techtimes.com/articles/3670/20140223/ netflix-verizon-standoff-only-net-neutrality-can-now-stop-video-slowdown.htm.

6. For a frequently cited example of harmful operation of a biased and discriminatory network, see Madison River Communications, LLC \& Affiliated Cos., 20 FCC Rcd. 4295, 4296-97 (2005) (describing how a small independent telephone company agreed to a $\$ 15,000$ monetary forfeiture and consent decree agreeing not to block Digital Subscriber Link customers' access to competitor's Voice over the Internet Protocol telephone service). 
and applications. ${ }^{7}$ Many advocates resort to hyperbole about real or predicted problems, but at either pole, the potential for false positives and false negatives appears quite likely. ${ }^{8}$

The former occurs when government regulatory agencies establish rules and regulations on an ex ante basis that incorrectly anticipates the need for oversight and marketplace intervention. ${ }^{9}$ Government oversight based on false conjecture and flawed forecasting can trigger unnecessary costs borne by ISPs and likely passed onto consumers. False negatives occur when actual harm to competition and consumers occurs without detection and remedy by the national regulatory authority or by subsequent (ex post) adjudication.

This Article will report on current issues in the ongoing network neutrality or open Internet debate with an eye toward identifying new stress points and opportunities for resolution. The Article concludes that developments in the Internet ecosystem will trigger more conflicts among ISPs and between ISPs and content providers. Increasingly, the Internet has become the primary broadband medium for information, communications, and entertainment (ICE), including an ever-increasing torrent of bit streams traveling from the Internet cloud downstream to individual subscribers served by "retail" ISPs that install the first- and last-mile connections providing consumers with access to the Internet cloud. ${ }^{10}$

7. Daniel L. Brenner, Creating Effective Broadband Network Regulation, 62 FeD. Comm. L.J. 13, 16 (2010) ("Those who advocate FCC involvement should recognize that resolution by administrative agency, as a first resort to solving oftenlegitimate questions about network behavior, is likely to produce worse public policies than nongovernmental forums. Ex ante network neutrality regulation of Internet network providers-like cable, wireline telephone, and wireless companies - poses risks for the continued development of the Internet that some network neutrality advocates minimize unrealistically.").

8. See, e.g., Jasper P. Sluijs, Network Neutrality Between False Positives and False Negatives: Introducing a European Approach to American Broadband Markets, 62 FED. COMM. L.J. 77 (2010).

9. Id. at 103 .

10. The Internet cloud refers to the vast array of interconnected networks that make up the Internet and provide users with seamless connectivity to these networks and the content available via these networks. "The increasing functionality of the Internet is decreasing the role of the personal computer. This shift is being led by the growth of 'cloud computing' - the ability to run applications and store data on a service provider's computers over the Internet, rather than on a person's desktop computer." William Jeremy Robison, Note, Free at What Cost?: Cloud Computing Privacy Under the Stored Communications Act, 98 GEO. L.J. 1195, 1199 (2010) (footnote omitted). 
Growing reliance on the Internet to deliver bandwidth-intensive video content to multiple screens has triggered more disputes on the technical way to interconnect networks as well as the financial compensation owed. How quickly and equitably parties can resolve their disputes will have a profound impact on whether governments need to intervene to ensure the existence of robust and sustainable competition as well as broadband networks capable of accommodating ever-increasing demand.

\section{CONVERgING TECHNOLOGIES AND MARKETS ADD NEW CHALLENGES}

The Internet has become an increasingly important medium for accessing much of the content previously available via several separate media, such as radio, television, newspapers, magazines, and the cinema. Converging technologies, such as digital traffic transmission, and addressing and routing standards, make it possible to use the Internet as a single platform for accessing content previously available only via several different media. Converging markets have begun to challenge the ability of content providers to create sequential and time-limited "windows" of access based on consumers' willingness to pay. For example, much of the video content currently transmitted by broadcasters and cable operators reaches a single screen, the television set, at a specific time and channel. Alternatives to this "appointment television" have begun to include "on demand" access anywhere and anytime using different display formats to computer monitors, smartphone screens, and tablets. ${ }^{12}$ Consumers can "stream" live content, now

11. "Consumers are changing their viewing habits in favor of 'TV Everywhere.' They no longer make 'appointments' to sit down and view content, and are no longer limited by TV programming schedules. They want content whenever and wherever they are." John Clancy, Why the Future of TV Is All About Personalization, MashaBle (Aug. 25, 2011), http://mashable.com/2011/08/25/tvmobile-personalization/.

12. Annual Assessment of the Status of Competition in the Mkt. for the Delivery of Video Programming, 27 FCC Rcd. 8610, 8613 (2012) (Fourteenth Report) ("Today, online viewers can watch television shows (including recently aired episodes); newly released and older movies; sporting events; and other content, including high-quality content produced specifically for online distribution. Online video, like the Internet itself, has migrated beyond the computer to a wide variety of devices since the last report. Consumers now can access OVD service via computers, smartphones, tablets, gaming consoles, smart television sets, Blu-ray players, and a host of consumer electronics products."). 
simulcasted via broadcast and other media. Additionally, they can download files containing content previously broadcasted and delivered via Multichannel Video Programming Distributors (MVPDs) ${ }_{13}^{13}$ such as cable and satellite television, and newly created content like the professional and amateur material available from YouTube. ${ }^{14}$

Convergence presents a near-term opportunity for broadcasters, MVPDs, telephone companies, and other creators and distributors of content to use the Internet as the primary means for reaching consumers. This outcome offers the benefits of greater efficiency and operating scale in the creation, distribution, and delivery of content. However, increasing reliance on the Internet as the primary medium for delivering all kinds of ICE content can trigger concentration of ownership and control as market shares increase for the few firms that dominate the Internet-access market. ${ }^{15}$ The possibility exists that

13. "As defined by statute, an MVPD is an entity that makes available for purchase multiple channels of video programming. Thus, the MVPD group includes cable operators, DBS [Direct Broadcast Satellite] operators, and telephone companies that offer multiple channels of video programming." Annual Assessment of the Status of Competition in the Mkt. for the Delivery of Video Programming, 28 FCC Rcd. 10,496, 10,503 (2013) (footnotes omitted) (Fifteenth Report).

14. The FCC uses the term Online Video Distributor (OVD) to identify Internet-based creators and distributors of video content. Annual Assessment of the Status of Competition in the Mkt. for the Delivery of Video Programming, 29 FCC Rcd. 1597, 1599 n.8 (2014).

An 'OVD' is any entity that offers video content by means of the Internet or other Internet Protocol (IP)-based transmission path provided by a person or entity other than the OVD. An OVD does not include an MVPD inside its MVPD footprint or an MVPD to the extent it is offering online video content as a component of an MVPD subscription to customers whose homes are inside its MVPD footprint.

Id. (citing Applications of Comcast Corp., Gen. Elec. Co. \& NBC Universal, Inc., 26 FCC Rcd. 4238, 4357 (2011)). "The issue of whether a certain type of OVD also qualifies as an MVPD under the Act and our regulations has been raised in pending program access complaint proceedings." Id. (citing Sky Angel U.S., LLC v. Discovery Commc'ns, LLC, No. CSR-8605-P (Mar. 24, 2010)).

15. See, e.g., FCC, MB DOCKET No. 14-90, DA 14-1129, COMMISSION SEeks Comment on Applications of AT\&T Inc. And DirectV to Transfer CONTROL OF FCC LiCEnses AND OTHER AUthORIZATIONS (2014), available at https://apps.fcc.gov/edocs public/attachmatch/DA-14-1129A1.pdf (proposing \$65 billion dollar acquisition of DirecTV by AT\&T); FCC, MB DOCKET No. 14-57, DA 14-986, COMMISSION SEeKS COMMENT ON APPLiCATIONS OF COMCAST Corporation, Time Warner Cable Inc., Charter Communications, Inc., And Spinco to ASSign AND TRANSFer CONTROL OF FCC LiCENSES AND OTHER AUtHORIZATIONS (2014), available at https://apps.fcc.gov/edocs_public/ 
a small number of conduit operators can acquire substantial market power, making it possible to affect the price and supply of Internetaccess conduits.

\section{A. Ex Ante Versus Ex Post Safeguards}

Advocates for ex ante government regulation of Internet access consider it essential that safeguards preclude ISPs from engaging in expected discriminatory and anticompetitive practices. ${ }^{16}$ The network neutrality debate addresses whether and how ISPs have the incentive and ability to provide preferential access to some content sources while handicapping others by providing inferior service, demanding unaffordable surcharges, or blocking specific types and sources of traffic. ${ }^{17}$

Opponents to such network neutrality oversight warn that any degree of government intervention will stifle innovation, investment, and freedom of expression. ${ }^{18}$ As the Internet grows in importance, the

attachmatch/DA-14-986A1.pdf (proposing \$45 billion dollar acquisition of Time Warner Cable by Comcast).

16. See, e.g., April Glaser, An Open Internet Is Essential to a Free Internet: Why Net Neutrality Should Matter to Everyone, ElECTRONIC FronTIER Found. (Sept. 10, 2014), https://www.eff.org/deeplinks/2014/09/open-internet-essentialfree-internet-why-net-neutrality-should-matter-everyone.

17. Preserving the Open Internet, 25 FCC Rcd. 17,905, 17,908-09 (2010) ("We noted the near-unanimous view that the Internet's openness and the transparency of its protocols have been critical to its unparalleled success. Citing evidence of broadband providers covertly blocking or degrading Internet traffic, and concern that broadband providers have the incentive and ability to expand those practices in the near future, we sought comment on prophylactic rules designed to preserve the Internet's prevailing norms of openness." (footnote omitted)), aff'd in part, vacated and remanded in part sub nom. Verizon v. FCC, 740 F.3d 623 (D.C. Cir. 2014), on remand Protecting and Promoting the Open Internet, 79 Fed. Reg. 37,448 (Jul. 1, 2014). While the D.C. Circuit Court of Appeals determined that the FCC lacked statutory authority to impose public utility, common carrier rules on ISPs, the FCC interpreted the court's decision as holding:

$[\mathrm{T}]$ hat the Commission had adequately justified the adoption of open Internet rules by finding that such rules would preserve and facilitate the "virtuous circle" of innovation, demand for Internet services, and deployment of broadband infrastructure and that, absent such rules, broadband providers would have the incentive and ability to inhibit that deployment.

Protecting and Promoting the Open Internet, 79 Fed. Reg. at 37,450-51 (citing Verizon, 740 F.3d at 644-46).

18. See, e.g., David Boaz, Net Neutrality-or Destroying Internet Innovation and Investment?, CATO LIBERTY (Sept. 2, 2014, 3:28 PM), 
network neutrality debate raises issues about the nature, composition, and features of next-generation networks that will provide broadband services to consumers. Network neutrality advocates believe that the Internet has become so essential to individual and societal welfare that ex ante rules and regulations are essential to keep the medium open, nondiscriminatory, and accessible by creators of content and services as well as end users. ${ }^{19}$ Opponents have an almost opposite view that government involvement would handicap the ability of the Internet to generate societal and individual benefits. ${ }^{20}$

\section{B. Can the Internet Ecosystem Self-Regulate?}

The network neutrality debate identifies a wide gap in assumptions about the competitiveness of the Internet-access marketplace as well as the ability of ISPs to self-regulate. As a mostly commercial medium, now largely owned and operated by private ventures, the Internet operates in a commercial environment where operators seek to maximize profits. However, many consumers, legislators, and regulatory officials believe that ISPs offer an essential service and accordingly have a duty to make their private networks affordable as well as accessible in a neutral and nondiscriminatory manner. ${ }^{21}$

http://www.cato.org/blog/net-neutrality-or-destroying-internet-innovationinvestment.

19. Glaser, supra note 16 ("The Internet is how we communicate and how we work, learn new things, and find out where to go and how to get there. It keeps us connected to those we love and informed of political events that affect our everyday lives. ... We depend on the Internet for everything we do, from our efforts to reform broken copyright laws, to our ongoing battles to end the NSA's illegal mass surveillance. More fundamentally, we know that the open Internet makes possible not just our activism, but the work of many others around the world... . Good net neutrality rules would forbid Internet providers from discriminating against sites that cannot afford to pay a toll for preferential treatment, or sites that are critical of Internet providers or undermine their business models.").

20. ROSLYN LAYTON, COMMENTS OF ROSLYN LAYTON 2 (2014), available at http://roslynlayton.com/wp-content/uploads/2014/07/Roslyn-Layton-NPRM-1428.pdf ("The FCC should not adopt sector specific net neutrality or 'Open Internet' rules. It has scant evidence for net neutrality violation; the academic literature about net neutrality has ambiguous conclusions about its benefits; and there is a not a general agreement of market failure needing fixing with net neutrality rules.").

21. See, e.g., Tim Wu, Comcast Versus the Open Internet, New Yorker (Feb. 24, 2014), http://www.newyorker.com/tech/elements/comcast-versus-theopen-internet; see also Susan Crawford, Introducing the Comcast Tax, BlOOMBERGVIEW (Feb. 24, 2014, 3:24 PM), http:/www.bloombergview.com/ articles/2014-02-24/introducing-the-comcast-tax. 
In the Internet's initial developing years, governments supported such openness through direct funding of research and development projects that created nondiscriminatory "best efforts" routing as the Internet's standard format for switching, routing, and delivering traffic. ${ }^{22}$ Even though governments for the most part have privatized their investments and private enterprises predominate, many consumers continue to believe that network owners have an ongoing obligation to support access much like the duties borne by public utilities that provide electricity, gas, water, and sewage processing. Going forward, the growing importance of the Internet highlights the importance in resolving debates over the Internet's future and the role, if any, of governments.

As the Internet evolves and matures, ISPs have begun to create increasingly diversified business models that deviate from offering undifferentiated service to everyone. In its early years of operation, ${ }^{23}$ the Internet operated as a neutral conduit offering nondiscriminatory routing of traffic based on technical formats, known as protocols, that required "best efforts" traffic routing. ${ }^{24}$ Additionally,

22. Philip J. Weiser, The Next Frontier for Network Neutrality, 60 ADMIN. L. REV. 273, 277-78 (2008) ("The Internet developed initially as an academic curiosity, based on a commitment to the 'end-to-end principle.' This principle requires that all Internet traffic, whether an email, a Voice over Internet Protocol (VoIP) 'call' or a video stream, be treated equally and managed through 'best efforts' connections. In such a network, data packets pass from one router to another without the prioritization of any particular packets. In practice, this means that Internet traffic reaches its destination at varying times, depending on the traffic levels of the relevant Internet communications links." (footnote omitted)).

23. For background on the history of Internet development, see Barry M. Leiner et al., Brief History of the Internet, INTERNET SOC'Y, http://www. internetsociety.org/internet/what-internet/history-internet/brief-history-internet (last visited Apr. 15, 2015); see also William B. Norton, The Evolution of the U.S. Internet Peering Ecosystem (Nov. 19, 2003) (unpublished manuscript), available at https://www.apricot.net/apricot2004/doc/cd_content/26th\%20February\%202004/Asi a\%20Pacific\%20Peering\%20Conference/01\%20-\%20Bill\%20norton/U.S.\%20

Peering\%20Ecosystem\%20v1.1.pdf.

24. Lyons, supra note 1, at 1035 ("The Internet is comprised of a series of 'best efforts' networks, each of which helps deliver any and all digital packets based upon the network's best guess as to how to forward each packet to its final destination. A critical element of this network architecture is that best efforts networks are indifferent as to the content of each packet. This functionality greatly reduces the cost of cyberspace innovation: As long as a service can be converted to digital packets, the network will facilitate its delivery to the consumer just like any other service in cyberspace. A developer needs only to write a program and place it on a public server, and the program is then immediately available to millions of Internet users worldwide." (footnotes omitted)). 
governments either owned and operated the Internet's transmission capacity, or provided funding for construction and operation by universities. ${ }^{25}$ The combination of taxpayer funding coupled with use of the same technical standards favored the offering of "plain vanilla," "one-size-fits-all" terms and conditions.

Government grants and subsidies initially foreclosed even the need for network operators to consider which users generated the most demand for service. With government subsidies, Internet operators had no incentive to meter traffic and to charge higher rates to heavy users. The lack of concern about who generated costs and "first in, first out" processing of packets established nondiscrimination as the standard operating procedure. Internet users assume that ISPs should continue to operate as neutral conduits, despite the fact that transmission formats and commercial incentives have changed and so too have consumer requirements. For example, consumers have a quick pain threshold for service degradation caused by actual network congestion, especially for access to "must see" television. ${ }^{26}$

Government funding and a default technical standard of neutrality initially eliminated any incentive for ISPs to favor certain types and sources of traffic. As the Internet evolved, governments privatized their investments and increasingly relied on the private sector to construct new facilities. The combination of a commercialized Internet and extraordinary marketplace success has motivated ISPs to consider pricing alternatives to unmetered, "all you can eat" service offered on an undifferentiated basis.

Having borne the financial responsibility to expand network capacity to accommodate growing demand, ISPs now want to recoup and profit from their infrastructure investments. Operating in what

One way to define a minimum level of access is as a requirement that broadband providers apply no less than a "best effort" standard to deliver traffic to end users. For any particular type of Internet traffic, best-effort delivery would represent the "typical" level of service for that type of traffic - in effect, routing traffic according to the "traditional" architecture of the Internet.

Protecting and Promoting the Open Internet, 79 Fed. Reg. 37,448, 37,462 (Jul. 1, 2014).

25. See Leiner et al., supra note 23.

26. See Rob Frieden, Internet Protocol Television and the Challenge of "Mission Critical" Bits, 33 CARdozo ARTS \& ENT. L.J. (forthcoming 2015) (manuscript at 2) (on file with author); see also Rob Frieden, The Impact of Next Generation Television on Consumers and the First Amendment, 24 FORDHAM INTELL. Prop. MEDia \& ENT. L.J. 61, 80 (2013). 
some economists refer to as a two-sided market, retail ISPs seek higher compensation from both downstream and upstream users of their networks. ${ }^{27}$ Retail ISPs have segmented service into different tiers and costs based on transmission delivery speeds and a monthly allotment of downloaded and uploaded content. They also demand additional compensation from upstream ISPs and content sources whose downstream traffic volumes exceed what upstream traffic the retail ISP can hand off.

Additionally, ISPs have considered offering ways to enhance the prospects of congestion-free traffic delivery. They characterize such "paid prioritization" 28 of traffic as lawful and desirable priceand-quality-of-service discrimination necessitated by the increasing torrent of bandwidth-intensive downstream traffic, such as Internet Protocol Television (IPTV) $)^{29}$ and other Over-the-Top (OTT) $)^{30}$

27. Dennis L. Weisman \& Robert B. Kulick, Price Discrimination, TwoSided Markets, and Net Neutrality Regulation, 13 Tul. J. TeCh. \& InTELl. Prop. 81, 87-88 (2010) ("Informally, a two-sided market can be thought of as a meeting place that brings together two distinct user groups, each of which benefits from the presence of the other. Examples include auctions, credit cards, dating bars, newspapers, video game consoles, and the Yellow Pages. No car auction would be possible without the presence of buyers willing to purchase and sellers willing to sell vehicles; thus, auctioneers must set their commissions to make sure there are a sufficient numbers of buyers and sellers at a given auction. In the case of heterosexual 'singles' bars, bar owners must attract both men and women and often set different prices for men and women to attract each gender in the desired proportions. Newspapers derive their revenues from both subscribers and advertisers; thus, the prices that newspapers set for subscribers and the prices they set for advertising space must be calibrated due to the fact that advertisers' willingness to pay will be determined by subscribership." (footnotes omitted)); see also Marc Rysman, The Economics of Two-Sided Markets, 23 J. ECON. PERSP. 125 (2009).

28. Tejas N. Narechania, Network Nepotism and the Market for Content Delivery, 67 StAn. L. REv. ONLINE 27, 29 (2014) ("[A] paid prioritization service allows broadband carriers to charge content providers for priority when allocating the network's shared resources, including the potentially scarce bandwidth over the last-mile connection between the Internet and an individual broadband subscriber. Such allocation has historically been determined by detached-or 'neutral'algorithms. The Commission's newly proposed rules, however, would allow carriers to subject this allocation to a content provider's ability and willingness to pay.").

29. IPTV offers consumers with broadband connection options to download video files or view (streaming) video content on an immediate "real time" basis. Sky Angel U.S., LLC, 25 FCC Rcd. 3879, 3879 (2010). Some of the available content duplicates what cable television subscribers receive, therein triggering disputes over whether cable operators can secure exclusive distribution agreements and prevent an IPTV service provider from distributing the same content. "Sky Angel has been providing its subscribers with certain Discovery networks for approximately two and a half years, including the Discovery Channel, Animal Planet, Discovery Kids 
applications that ride on a broadband connection. For ventures offering these kinds of bandwidth-intensive applications, ISPs have begun to offer "most favored nation" treatment of such "mission critical" packets in exchange for higher compensation. ${ }^{31}$ Because a "best efforts" routing standard might not guarantee sufficiently high quality of service in the downloading and immediate viewing of "streaming" video content, subscribers now expect ISPs and content sources, such as Netflix, to make the necessary arrangements to ensure timely delivery of video packets.

Changes in the technical capabilities of the Internet coupled with greater demand for faster and higher capacity bit transmission have created new incentives for ISPs to devise ways to offer different tiers of service based on the speed and volume of traffic handled. ${ }^{32}$ Faster delivery speeds or higher monthly capacity allowances do not constitute unfair price-and-quality-of-service discrimination, because any subscriber can opt for a superior service options at a higher charge commensurate with the higher costs incurred by an ISP. Similarly, few would object to financial arrangements that reduce the time it takes to deliver content, a factor commonly referred to as

Channel, Planet Green, and the Military Channel. Sky Angel submits that these channels are a significant part of its service offering." Id. at 3879-80 (footnote omitted). For background on IPTV, see generally In-Sung Yoo, Comment, The Regulatory Classification of Internet Protocol Television: How the Federal Communications Commission Should Abstain from Cable Service Regulation and Promote Broadband Deployment, 18 CommLaw ConspeCtus 199 (2009).

30. "Over-the-top VoIP [and other] services require the end user to obtain broadband transmission from a third-party provider, and providers of over-the-top [services] can vary in terms of the extent to which they rely on their own facilities." Preserving the Open Internet, 25 FCC Rcd. 17,905, 17,916 n.48 (2010), aff'd in part, vacated and remanded in part sub nom. Verizon v. FCC, 740 F.3d 623 (D.C. Cir. 2014), on remand Protecting and Promoting the Open Internet, 79 Fed. Reg. 37,448 (Jul. 1, 2014).

31. "Today, much Web content is not delivered to the ultimate recipient directly from the Web server belonging to the original creator, but via a content delivery network $(\mathrm{CDN})$ - a collection of servers that cache the content and deliver it on demand." David D. Clark \& Marjory S. Blumenthal, The End-To-End Argument and Application Design: The Role of Trust, 63 FeD. Comm. L.J. 357, 36465 (2011).

32. See Christopher S. Yoo, Innovations in the Internet's Architecture that Challenge the Status Quo, 8 J. on Telecomm. \& High Tech. L. 79, 84 (2010) (outlining new ISP interconnection variations of peering and transiting). 
latency. ${ }^{33}$ Companies such as Akamai reduce latency by installing proxy servers to distribute content closer to end users. ${ }^{34}$

However, network neutrality concerns arise when an ISP proposes to prioritize traffic delivery, particularly for the last-mile link to retail ISP subscribers. Opponents fear that retail ISPs will impose "pay to play" surcharges based on their ability to control whether and how well traffic reaches end users. ${ }^{35}$ The possibility exists that ISPs will ration access to their networks and deliberately slow or delay the delivery of non-premium service traffic. Retail ISPs possibly can create artificial congestion while claiming that service degradation results from legitimate tactics designed to apportion scarce and overtaxed network capacity in response to extreme demands for service. ${ }^{36}$

33. Latency refers to the time it takes for upstream or downstream traffic to arrive at its intended destination. Some applications, such as computer gaming, requires fast response times to service requests and therefore very low latency.

Communicating with a geosynchronous satellite orbiting the earth at a distance of greater than $36,000 \mathrm{~km}$ results in a round trip latency of about 500 [milliseconds (ms)]. The necessary signaling between the set-top box and the satellite controller, to request assignment of a communication channel, can double this to over $1000 \mathrm{~ms}$, which would precluded [sic] use of many latency-sensitive services. In contrast, the maximum average latency found in our surveys for terrestrial technologies is less than $70 \mathrm{~ms}$.

FCC's Office of Eng'g \& Tech. \& Consumer \& Governmental Affairs Bureau, A Report on Consumer Wireline Broadband Performance in the U.S., FCC (footnote omitted), http://www.fcc.gov/reports/measuring-broadband-america-2014\#Findings (last visited Apr. 15, 2015).

34. Akamai Techs., Inc., Turbo-Charging Dynamic Web Sites with AKAmAi EdGESuite 1, 3 (2001), available at http://www.andrew.cmu.edu/course/ 15-749/READINGS/optional/Akamai_EdgeSuite_Turbocharging_Websites.pdf.

35. See Lyons, supra note 1 , at 1035 ("If broadband providers departed from the best efforts principle and instead prioritized certain packets over others on the basis of content, they could distort the market for Internet content and applications. As Professors Lessig and $\mathrm{Wu}$ explain, prioritization 'threaten[s] to replace survival-of-the-fittest with survival-of-the-favored.' Rather than allowing competition to shape the market for Internet content, broadband providers could pick and choose winners by prioritizing favored competitors. And if broadband providers could charge for priority delivery, they would dramatically raise the cost of Internet innovation by requiring programmers to pay a toll before their products could reach consumers. This could shift power toward well-funded corporate developers and away from the garage-programmers whose innovations have made the Internet what it is." (footnote omitted) (quoting Letter from Lawrence Lessig \& Tim Wu, to Marlene H. Dortch, Sec'y, FCC 6 (Aug. 22, 2003), available at http://timwu.org/wu_lessig_fcc.pdf)).

36. "The routing of data on the Internet is a zero-sum game. Unless there is continual congestion, no website would pay for priority treatment. This means the FCC's proposed rules will actually produce a strong incentive for ISPs to create 
Network neutrality advocates worry that the option to accommodate users' diversifying traffic requirements will provide ISPs the opportunity to favor the traffic of corporate affiliates and other ventures that voluntarily or reluctantly agree to pay surcharges to abate real or fake congestion. ${ }^{37}$ Advocates for neutrality argue that paid prioritization will make it possible for ISPs to create fast-traffic links, available for a premium payment with everyone else relegated to slow lanes. ${ }^{38}$ Worse yet, they worry that ISPs can degrade basic service to such an intolerably slow speed that most, if not all, content ventures would have to migrate to "premium" service. A start-up video venture, with limited funding, could experience congestion even for an insignificant volume of traffic that previously got delivered without any problem.

The substantial cost in accommodating subscriber demand for fast broadband connections necessitates ISP efforts to diversify

congestion through artificial scarcity." Timothy Karr, FCC Proposal for a Payola Internet Would End Net Neutrality, FreE Press (Apr. 25, 2014), http://www.freepress.net/press-release/106177/fcc-proposal-payola-internet-wouldend-net-neutrality.

37. See Lyons, supra note 1, at 1034 ("By regulating the terms upon which content providers use their networks to reach consumers, broadband providers could manipulate the flow of information in society. For example, Comcast could conceivably block consumer access to websites like www.comcastsucks.org that criticize the company. Perhaps more realistically, Comcast could block or degrade content and applications like Netflix that compete against its other revenuegenerating services. Unlike America Online and other first-generation dial-up Internet access providers, most broadband providers do not specialize in providing Internet access alone. Rather, the largest broadband providers are cable and telephone companies, which have incentives to prevent customers from using their broadband connections in ways that threaten their other revenue streams. For example, consumer groups have expressed concerns that broadband Internet providers that also offer on-demand movie rentals via cable might discriminate against other services (such as Netflix or BitTorrent) that make movies available over a broadband connection." (footnotes omitted)).

38. Michael Weinberg, How the FCC's Proposed Fast Lanes Would Actually Work, PuB. KNOwledge (May 16, 2014), https://www.publicknowledge. org/news-blog/blogs/how-the-fccs-proposed-fast-lanes-would-actually-work ("Once there is a split internet, ISPs have the incentive to push every new innovation towards the fast lane. Innovation in the fast lane means extra revenue, while innovation in the slow lane gets them nothing. Investments that would have gone into the entire network before the split will now only go into the fast lane. That means that the forces that have traditionally increased speeds for everyone will now be reserved for those who can pay extra. All the while, the slow lane just keeps getting slower in comparison. After all, a slow slow lane makes the premium fast lane an even better value!"). 
service offerings on the basis of subscriber bandwidth requirements and other customer-specific demand characteristics. ISPs have identified new strategies to differentiate their offerings on the basis of price, quality of service, transmission speeds, permissible amount of capacity uploaded and downloaded, legitimate networkmanagement objectives, traffic treatment during congestion, and the demand for customer-specified network features. However, additional anticompetitive strategies include deliberately blocking traffic or dropping packets and rationing access to ample delivery facilities with an eye toward extracting surcharges or favoring a corporate affiliate.

Changing market conditions support ISP efforts to customize service, but the technical means used to achieve this goal have proven controversial. Advocates for restricting price and service discrimination contend that absent a network neutrality mandate, ISPs will use techniques to discriminate in ways that harm competitors and consumers. ${ }^{39}$ Network neutrality supporters claim that ISPs have both the incentive and ability to engage in harmful discrimination, typically framed as necessary network management or a legitimate response to the specific requirements of a customer. The worst-case scenario envisioned by network neutrality advocates sees a reduction in innovation, efficiency, consumer benefits, and national productivity. ${ }^{40}$

ISPs vehemently claim that they would never meddle with customers' traffic absent a compelling network management justification. However, national regulatory authorities, including the Federal Communications Commission (FCC), have uncovered some instances of intentional service degradation and traffic blocking. The FCC determined that a rural telephone company had deliberately prevented its subscribers from accessing Voice over the Internet Protocol (VoIP) telephone services that provide a competitive alternative to the telephone company's Digital Subscriber Link,

39. Verizon v. FCC, 740 F.3d 623, 646 (D.C. Cir. 2014) ("The Commission also convincingly detailed how broadband providers' position in the market gives them the economic power to restrict edge-provider traffic and charge for the services they furnish edge providers. Because all end users generally access the Internet through a single broadband provider, that provider functions as a 'terminating monopolist' with power to act as a 'gatekeeper' with respect to edge providers that might seek to reach its end-user subscribers." (citations omitted)).

40. See Weinberg, supra note 38. 
broadband service. ${ }^{41}$ The Commission also sanctioned Comcast for meddling with file transfers of subscribers containing content that offered a substitute to the company's pay-per-view movie service. ${ }^{42}$

\section{CDN-Retail ISP Conflicts}

A lesser-known controversy occurred when Level 3, a major broadband telecommunications carrier, contracted with Netflix to serve as its primary distributor of online video content. Level 3 agreed to serve as a Content Delivery Network (CDN) thereby accepting the technical, operational, and financial responsibility to arrange for timely and high-quality delivery of Netflix traffic to the company's subscribers via retail ISPs such as Comcast. By definition, CDNs generate substantially more traffic requiring downstream delivery than they likely will receive from downstream ISPs seeking to offset the volume with upstream traffic. In response to the increase in terminating traffic generated by Level 3, Comcast, acting in the capacity as a retail ISP providing last mile delivery of Netflix traffic, demanded additional compensation. Level 3 objected, claiming that Comcast had in effect installed an Internet toll booth with an eye toward competitively handicapping Netflix vis-à-vis Comcast's video on demand service that also delivers recent movies and other premium television content. ${ }^{43}$ Comcast asserted that it simply had responded to a traffic imbalance that triggered the need for modification ${ }^{44}$ to an existing peering arrangement. ${ }^{45}$

41. Madison River Commc'ns, LLC \& Affiliated Cos., 20 FCC Rcd. 4295, 4297 (2005).

42. Formal Complaint of Free Press \& Pub. Knowledge Against Comcast Corp. for Secretly Degrading Peer-to-Peer Applications, 23 FCC Rcd. 13,028 (2008), vacated, Comcast Corp. v. FCC, 600 F.3d 642 (D.C. Cir. 2010) (deeming the FCC to have exceeded its statutory authority when responding to a complaint and imposing network neutrality rules).

43. Level 3 Communications Issues Statement Concerning Comcast's Actions, MARKET WATCH (Nov. 29, 2010, 4:38 PM), http://www.marketwatch.com/ story/level-3-communications-issues-statement-concernings-comcasts-actions-201011-29/reflink=MW_news_stmp.

44. Joe Waz, 10 Facts About Peering, Comcast and Level 3, COMCAST (Nov. 30, 2010), http://corporate.comcast.com/comcast-voices/10-facts-aboutpeering-comcast-and-level-3; Joe Waz, Comcast Comments on Level 3, CoMCAST (Nov. 29, 2010), http://corporate.comcast.com/comcast-voices/comcast-commentson-level-3.

45. For background on the peering process, see Geoff Huston, Internet Peering and Settlements, APNIC, https://www.apnic.net/community/ecosystem/ $\mathrm{i}^{*}$ orgs/number-misuse/internet-peering-and-settlements (last visited Apr. 15, 2015); 
Under ordinary circumstances, when the volume of traffic exchanged between Internet carriers changes and becomes unbalanced, the carrier generating more traffic than it receives bears the financial obligation to compensate the terminating carrier. ${ }^{46}$ However, ISPs typically seek to balance out the traffic if possible before demanding additional compensation. For ISPs that concentrate on the downstream delivery of content, an offsetting upstream flow of traffic may not be available to forestall a surcharge. However, in the dispute between Level 3 and Comcast, Level 3 operates a large transcontinental network that could handle more upstream traffic from Comcast had Comcast elected to offset the Netflix downstream traffic volume with upstream traffic that otherwise would travel via Comcast's long-haul network or other ISP networks. Additionally, Comcast generates sizeable broadband subscription revenues from end users who have every expectation that the company will honor its service commitment regardless of whether it can extract supplemental payment from Netflix or its CDNs. $^{47}$

Level 3 sought to frame its dispute with Comcast as one involving network neutrality and the ability of downstream ISPs to use their distribution-channel monopoly to extract unfair financial concessions from content providers. Level 3 insisted that because retail ISPs receive ample Internet-access subscription fees from their customers, no additional payments should come from content providers. Comcast framed the issue narrowly as an interconnection matter between an upstream ISP and the ISP providing last-mile termination.

see also DrPeering.net: Resources to Make Strategic Peering Decisions, DRPEERING INT'L, http://drpeering.net/index.php (last visited Apr. 15, 2015).

46. Daniel L. Brenner \& Winston Maxwell, The Network Neutrality and the Netflix Dispute: Upcoming Challenges for Content Providers in Europe and the United States, InTEll. Prop. \& TeCH. L.J., Mar. 2011, at 3, 5 ("Currently, agreements for the exchange of Internet traffic are unregulated and left solely to commercial negotiation between Internet backbone providers. Agreements for the exchange of traffic between operators are called 'peering agreements' and depending on the balance of traffic, it may be either free or paid. Other arrangements provide that one network will carry traffic without exchanging traffic on that network link. This will involve payment, and such service is called 'transit."').

47. "Broadband is an extraordinarily profitable service. Top Wall Street analysts John Hodulik of UBS and Craig Moffett of Bernstein both report broadband margins of $90 \%$ based on official company filings." Wireline Costs and Caps: A Few Facts, FAST NET NEWs, http://fastnetnews.com/dslprime/42-d/4148-costs-andcaps (last visited Apr. 15, 2015). 
This dispute and one involving Netflix and Comcast, discussed later in this Article, provide evidence that interconnection disputes between carriers have great potential for inconveniencing consumers and raising their costs for accessing Internet-mediated content. Simply having competitive alternatives does not immediately help consumers, because the pain threshold for blocked or degraded content begins well before one can find a suitable replacement. Even if broadband consumers have alternatives to the currently used ISP, embroiled in interconnection and carriage disputes, the migration to an alternative carrier would occur after the telecast of "must see" content, such as a football game, and probably would trigger added expense and inconvenience.

Nations throughout the world have addressed the network neutrality debate in different ways. The range of strategies runs the gamut from the national legislature imposing strict nondiscrimination requirements, e.g., Brazil, Chile, and the Netherlands, to doing nothing at all. ${ }^{48}$ Inside these two poles, some nations use a market analysis that would trigger government intervention if ISPs, individually or collectively, have acquired too much market power, e.g., nations in the European Union and Australia. ${ }^{49}$ Other nations, such as Canada and France, have opted to apply some or all of the regulatory safeguards applicable to telecommunications services instead of classifying Internet access as nonessential, private carriage. ${ }^{50}$

48. See, e.g., Kevin J. O’Brien, Dutch Lawmakers Adopt Net Neutrality Law, N.Y. Times (Jun. 22, 2011), http://www.nytimes.com/2011/06/23/technology/ 23neutral.html?pagewanted=all\&_r $=0$. "In Brazil this week, lawmakers approved a net neutrality provision that bars telecom companies from charging higher rates for access to content that uses more bandwidth." Mark Scott, U.S. Plan for Internet Fast Lanes Contrasts with European Rules, N.Y. TiMEs (Apr. 24, 2014, 9:20 AM), http://bits.blogs.nytimes.com/2014/04/24/u-s-plan-for-internet-fast-lanes-contrastswith-european-rules/.

49. See Digital Agenda for Europe: A Europe 2020 Initiative, supra note 4; see also Council of the European Union, Proposal for a Regulation of the EUROPEAN PARLIAMENT AND OF THE COUNCIL LAYING DOWN MEASURES Concerning the European Single Market for Electronic Communications AND TO ACHIEve A CONNECTED CONTINENT, AND AMENDing Directives 2002/20/EC, 2002/21/EC, 2002/22/EC, AND REgulations (EC) No 1211/2009 AND (EU) No 531/2012 (2014), available at https://edri.org/wp-content/uploads/ 2013/09/Note-NN-14.11.2014.pdf (proposing less rigorous safeguards).

50. See Review of the Internet Traffic Management Practices of Internet Service Providers, CAN. Radio-Television \& TeleComm. Commission (Oct. 21, 2009), http://www.crtc.gc.ca/eng/archive/2009/2009-657.htm. 


\section{Recurring Litigation and Uncertainty}

In the United States, the FCC has struggled to find direct or indirect statutory authority to impose lawful ex ante network neutrality rules. The Commission's regulatory quandary largely results from a decision made in 2005 that ISPs offer largely unregulated information services and not telecommunications services for which the Commission has clear statutory authority to regulate. ${ }^{51}$ On two separate occasions, a reviewing court largely rejected efforts by the FCC to assert jurisdiction to establish rules that anticipate, sanction, and remedy anticompetitive and discriminatory ISP practices. ${ }^{52}$ Judicial review has clearly stated that the FCC does not have statutory authority to establish rules prohibiting discrimination and content blocking by ISPs in light of the Commission's lack of authority to impose common-carrier duties on ISPs. ${ }^{53}$ Having determined that broadband Internet access constitutes an information service, ${ }^{54}$ the FCC effectively abandoned the option of establishing ex ante regulations, because it no longer had the jurisdiction to do so.

The D.C. Circuit Court of Appeals first held that the FCC could not sanction Comcast for using software to disable peer-to-peer file sharing by subscribers even though the company did not need to remedy congestion and had financial incentives to prevent subscribers from sharing movies it might otherwise lease from Comcast on a pay-per-view basis. ${ }^{55}$ The court determined that the

51. Time Warner Telecom, Inc. v. FCC, 507 F.3d 205, 214 (3d Cir. 2007); Appropriate Framework for Broadband Access to the Internet Over Wireline Facilities, 20 FCC Rcd. 14,853 (2005); see also Nat'l Cable \& Telecomms. Ass'n v. Brand X Internet Servs., 545 U.S. 967, 1002-03 (2005) (deferring to FCC expertise and affirming its classification of broadband Internet access an information service).

52. See Verizon v. FCC, 740 F.3d 623, 655 (D.C. Cir. 2014); Comcast Corp. v. FCC, 600 F.3d 642, 661 (D.C. Cir. 2010).

53. See Rob Frieden, The Rise of Quasi-Common Carriers and Conduit Convergence, 9 J.L. \& POL'Y INFO. SoC'Y 471, 473 (2014).

54. Nat'l Cable \& Telecomms. Ass'n, 545 U.S. at 977-78; Time Warner Telecom, Inc., 507 F.3d at 217; Appropriate Regulatory Treatment for Broadband Access to the Internet over Wireless Networks, 22 FCC Rcd. 5901, 5901 (2007); United Power Line Council's Petition for Declaratory Ruling Regarding the Classification of Broadband over Power Line Internet Access Serv. as an Info. Serv., 21 FCC Rcd. 13,281, 13,281 (2006); Appropriate Framework for Broadband Access to the Internet over Wireline Facilities, 20 FCC Rcd. 14,853, 14,863 (2005); Inquiry Concerning High-Speed Access to the Internet over Cable and Other Facilities, 17 FCC Rcd. 4798, 4821 (2002).

55. Comcast Corp., 600 F.3d at 656-60. 
FCC had no direct statutory authority to impose network neutrality obligations on information service providers nor could the Commission assert "ancillary jurisdiction" 56 based on its duty to ensure that new technologies do not adversely impact regulated services.

In its review of the FCC's second attempt to establish jurisdiction over ISPs, the D.C. Circuit Court of Appeals again rejected common carrier rules requiring nondiscrimination and prohibiting traffic blocking. ${ }^{57}$ However, the court did agree with the

56. The FCC relies on a claim of ancillary jurisdiction when the Commission lacks explicit statutory authority. The FCC successfully invoked ancillary jurisdiction to regulate cable television even before the Commission received a statutory mandate to do so.

The FCC needed a hook to assert jurisdiction over cable. To reach that goal, it used a two-step process. First, the Commission found that cable was within its primary statutory grant of authority under $\S 152$ (a) of the [Communications] Act, which allows the FCC to regulate "all interstate and foreign communication by wire or radio." Second, the FCC invoked $\S 303(r)$ of the Act, which allows the Commission to issue "such rules and regulations and prescribe such restrictions and conditions, not inconsistent with law," as "public convenience, interest, or necessity requires." The FCC also referenced $\S 154(i)$, which provides that "[t]he Commission may perform any and all acts, make such rules and regulations, and issue such orders, not inconsistent with [the Communications Act], as may be necessary in the execution of its functions." Kevin Werbach, Off the Hook, 95 CoRnell L. REV. 535, 572 (2010) (second and third alterations in original) (footnotes omitted). See generally John Blevins, Jurisdiction as Competition Promotion: A Unified Theory of the FCC's Ancillary Jurisdiction, 36 Fla. ST. U. L. REV. 585 (2009); Andrew Gioia, FCC Jurisdiction over ISPS in Protocol-Specific Bandwidth Throttling, 15 MicH. Telecomm. \& TeCH. L. Rev. 517 (2009); James B. Speta, The Shaky Foundations of the Regulated Internet, 8 J. ON Telecomm. \& High TECH. L. 101 (2010).

On several occasions, the Supreme Court has affirmed the FCC's claim of ancillary jurisdiction. United States v. Midwest Video Corp., 406 U.S. 649, 670 (1972); United States v. Sw. Cable Co., 392 U.S. 157, 180-81 (1968); see also Chevron, U.S.A., Inc. v. Natural Res. Def. Council, Inc., 467 U.S. 837 (1984). The Supreme Court supports deferral to the expertise of a regulating agency "[i]f the intent of Congress is clear." Chevron, 467 U.S. at 842. If "Congress has not directly addressed the precise question at issue," and the agency has acted pursuant to an express or implied delegation of authority, the agency's statutory interpretation is entitled to deference, as long as it is reasonable. Id. at 843-44; see also United States v. Mead Corp., 533 U.S. 218, 226-27 (2001).

57. Verizon, 740 F.3d at 628 ("[E]ven though the Commission has general authority to regulate in this arena, it may not impose requirements that contravene express statutory mandates. Given that the Commission has chosen to classify broadband providers in a manner that exempts them from treatment as common carriers, the Communications Act expressly prohibits the Commission from nonetheless regulating them as such. Because the Commission has failed to establish that the anti-discrimination and anti-blocking rules do not impose per se common 
FCC that it could impose non-common carrier rules based on the FCC's reading of $\S 706$ in the Communications Act, which authorizes the Commission to assess the availability of nationwide access to advanced services such as the Internet and to take steps to promote more access if market forces prove inadequate. ${ }^{58}$

In March 2015, the FCC substantially changed its regulatory approach to network neutrality. Rather than act on a reviewing court's invitation to impose non-common carrier, network neutrality rules, the Democratic majority of the FCC opted for clearer and more muscular ex ante rules on remand. ${ }^{59}$ The FCC opted to reclassify elements of Internet access as a Title-II regulated, common carrier service $^{60}$ with no distinction between wireline and wireless ISPs. ${ }^{61}$ The Commission will have to convince a reviewing court that the decision to reclassify broadband service as common carriage resulted from rational decision making based on a complete record evidencing substantially changed circumstances occurring in the ten years running from 2005, when the FCC opted to classify Internet access as an information service. ${ }^{62}$

carrier obligations, we vacate those portions of the Open Internet Order." (emphasis omitted)).

58. 47 U.S.C. $§ 1302(a)(2012)$.

59. See generally Protecting and Promoting the Open Internet, $2015 \mathrm{WL}$ 1120110, ๆ甲 14-24, at *5-7 (2015).

60. Id. $\uparrow 25$, at $* 8$.

61. Id. The FCC previously had imposed less stringent rules on wireless carriers in light of spectrum use, greater potential for congestion, and recent entry in broadband markets. The 2015 Open Internet Order treats wireless ISPs no differently than wireline ISPs: "Today, we find that changes in the mobile broadband marketplace warrant a revised approach. We find that the mobile broadband marketplace has evolved, and continues to evolve, but is no longer in a nascent stage. As discussed below, mobile broadband networks are faster, more broadly deployed, more widely used, and more technologically advanced than they were in 2010. We conclude that it would benefit the millions of consumers who access the Internet on mobile devices to apply the same set of Internet openness protections to both fixed and mobile networks." $I d$. $\mid 88$, at *24.

62. "It is also well settled that we may reconsider, on reasonable grounds, the Commission's earlier application of the ambiguous statutory definitions of 'telecommunications service' and 'information service." Id. \334, at *93.

The [Supreme] Court's application of th[e] Chevron test in Brand X makes clear our delegated authority to revisit our prior interpretation of ambiguous statutory terms and reclassify broadband Internet access service as a telecommunications service. The Court upheld the Commission's prior information services classification because "the statute fails unambiguously to classify the telecommunications component of cable modem service as a distinct offering. This leaves federal telecommunications policy in this technical and complex area to be set by 
The FCC emphasized the need for narrowly crafted rules designed to "prevent specific practices we know are harmful to Internet openness - blocking, throttling, and paid prioritization - as well as a strong standard of conduct designed to prevent the deployment of new [anticompetitive] practices that would harm Internet openness." ${ }^{\prime 3}$ The Commission emphasized that ISPs have both the incentive and ability to leverage access in ways that can thwart the virtuous cycle of innovation and investment in the Internet ecosystem:

The key insight of the virtuous cycle is that broadband providers have both the incentive and the ability to act as gatekeepers standing between edge providers and consumers. As gatekeepers, they can block access altogether; they can target competitors, including competitors to their own video services; and they can extract unfair tolls. ${ }^{64}$

The FCC emphasized that while subjecting ISPs to Title-II, common-carrier oversight, the Commission will quite narrowly use its statutory authority as evidenced by the decision to forbear ${ }^{65}$ from applying " 27 provisions of Title II of the Communications Act, and

the Commission ...." Where a term in the Act "admit[s] of two or more reasonable ordinary usages, the Commission's choice of one of them is entitled to deference." The Court concluded, given the "technical, complex, and dynamic" questions that the Commission resolved in the Cable Modem Declaratory Ruling, "[t]he Commission is in a far better position to address these questions than we are."

Id. $\uparrow 332$, at 92 (citations omitted).

63. $I d$. $₫ 4$, at $* 3$.

64. Id. $\uparrow 20$, at $* 7$.

65. 47 U.S.C $§ 160$ (a) (1996). This statute authorizes the FCC to streamline the scope of its Title II oversight by forbearing from applying many common carrier requirements:

[T] he Commission shall forbear from applying any regulation or any provision of this chapter to a telecommunications carrier or telecommunications service, or class of telecommunications carriers or telecommunications services, in any or some of its or their geographic markets, if the Commission determines that-(1) enforcement of such regulation or provision is not necessary to ensure that the charges, practices, classifications, or regulations by, for, or in connection with that telecommunications carrier or telecommunications service are just and reasonable and are not unjustly or unreasonably discriminatory; (2) enforcement of such regulation or provision is not necessary for the protection of consumers; and (3) forbearance from applying such Id. provision or regulation is consistent with the public interest. 
over 700 Commission rules and regulations." ${ }_{66}$ The Commission recognized the need to explain how the new requirements satisfy pressing needs, but in the most narrow and well calibrated matter in light of virulent opposition from most ISPs and the two Republican Commissioners. The Order reports that "there will be fewer sections of Title II applied than have been applied to Commercial Mobile Radio Service (CMRS)[ the regulatory classification for wireless voice telecommunications service], where Congress expressly required the application of Sections 201, 202, and 208, and permitted the Commission to forbear from others. In fact, Title II has never been applied in such a focused way." ${ }^{67}$

In addition to the specific prohibitions on blocking, throttling, and paid prioritization, the FCC established a general prohibition on ISP practices that would unreasonably interfere with or disadvantage downstream consumers and upstream edge providers of content, applications, and services. ${ }^{68}$ The Commission will consider on a case-by-case basis whether an ISP has engaged in a practice "that unreasonably interfere[s] with or unreasonably disadvantage[s] the ability of consumers to reach the Internet content, services, and applications of their choosing or of edge providers to access consumers using the Internet." ${ }^{69}$ The Commission opted to apply a more flexible evaluation rather than use a single commercial reasonableness standard that it had proposed in the 2014 Open Internet NPRM. The Commission concluded that it should "adopt a governing standard that looks to whether consumers or edge providers face unreasonable interference or unreasonable disadvantages, and makes clear that the standard is not limited to whether a practice is agreeable to commercial parties." ${ }^{70}$

66. $2015 \mathrm{WL} 1120110$, 9 , at $* 3$. The major provisions of Title II that the Order will apply are: nondiscrimination and no unjust and unreasonable practices under $\S \S 201$ and 202, id. ๆף 195, 289, at *56,*80; authority to investigate complaints and resolve disputes under $\S 208$ and related enforcement provisions, specifically $\S \S 206,207,209,216$ and 217, id. 9ף 193, at $* 55$; protection of consumer privacy under $\S 222, i d$. 153 , at $* 14$; fair access to poles and conduits under $\S 224$, id. $\uparrow 56$, at *15; protection of people with disabilities under $\S \S 225$ and 255 , id. 155 , at *15; and providing universal funding for broadband service, but not the requirement to collect contributions to such funding through partial application of $\S 254, i d$. $\llbracket 57$, at $* 15$.

67. Id. 138 , at $* 10$.

68. Id. 108 , at $* 30$.

69. Id. 135 , at $* 37$.

70. Id. I 150, at $* 41$. The FCC identified a number of factors it will consider in future evaluations. Id. 1 ๆ 139-45, at*39-40. These include an assessment whether a practice allows end-user control and is consistent with promoting 
The FCC reported that it will use the "no-unreasonable interference/disadvantage" standard to evaluate controversial subjects including the lawfulness of "sponsored data" arrangements where an ISP accepts advertiser payment in exchange for an agreement not to meter and debit the downstream traffic delivery. ${ }^{71}$ The Commission also will use this standard to consider the lawfulness of data caps that tier service by the amount of permissible downloading volume. ${ }^{72}$ In both instances, the FCC sees the potential for an ISP to create artificial scarcity to extract higher revenues, to favor corporate affiliates and third parties willing to pay a surcharge as well as the potential for disadvantaging competitors, e.g., using data caps to harm new vendors of video programming that compete with an ISP service. ${ }^{73}$ On the other hand, the Commission recognizes that service tiering can promote innovation and new, customized services. $^{74}$

The Order expresses the view that reclassifying Internet access as a telecommunications service provides the strongest legal foundation for the Open Internet regulations, coupled with a secondary reference to $\S 706$ of the Telecommunications Act of 1996 and Title III, which addresses the use of radio spectrum and applies common carriage regulation to wireless voice carriers. ${ }^{75}$ By using the stronger Title II foundation, the FCC asserts that it can establish

consumer choice; whether a practice has anti-competitive effects; whether consumers and opportunities for free expression are promoted or harmed; whether there is an the effect on innovation, investment, or broadband deployment; whether the practice hiders the ability of end users or edge providers to use broadband access to communicate with each other; and whether a practice conforms to best practices and technical standards adopted by open, broadly representative, and independent Internet engineering, governance initiatives, or standards-setting organization. Id.

71. Id. $\mid 152$, at $* 42$.

72. Id. $₫ 153$, at $* 42$.

73. Id. $₫$ ๆ $151-53$, at $* 42$.

74. Id.

75. Id. 9 - 273-74, at *76.

We ground the open Internet rules we adopt today in multiple sources of legal authority-section 706, Title II, and Title III of the Communications Act. We marshal all of these sources of authority toward a common statutorily-supported goal: to protect and promote Internet openness as platform for competition, free expression and innovation; a driver of economic growth; and an engine of the virtuous cycle of broadband deployment.

We therefore invoke multiple, complementary sources of legal authority. As a number of parties point out, our authority under section 706 is not mutually exclusive with our authority under Titles II and III of the Act.

Id. 
clear and unconditional statutory authority, but also use the flexibility contained in Title II to forbear from applying most common carrier requirements not relevant to modern broadband service just as occurs for wireless telephone service. ${ }^{76}$ However, with a Title II regulatory foundation, the Order makes it possible for the FCC to create an open Internet conduct standard that ISPs cannot harm consumers or edge providers with enforcement tools available to sanction violations. ${ }^{77}$

The Commission's decision to treat aspects of Internet access as common carriage certainly will trigger a third judicial appeal and review whether such reclassification constitutes a reasonable decision based on a complete evidentiary record. By opting for the reclassification option, the FCC underscores the riskiness in imposing ex ante regulation without an explicit legislative mandate.

The FCC's approach requires great finesse. On one hand, it cannot impose clear common-carrier duties on ISPs, unless it can convince an appellate court of the rationality in the reclassification from information service to telecommunications service. On the other hand, the Commission wants to create ex ante rules that can foreclose anticompetitive practices while allowing ISPs to engage in commercial negotiations, possibly providing alternatives to plain vanilla, best-efforts management of Internet traffic. The FCC proposes ad hoc review of complaints about specialized trafficmanagement arrangements that arguably provide "better than best efforts" routing options for single ventures. However, the Commission does not want this option to result in a balkanized Internet having fast lanes available to ventures with deep pockets and slow lanes available to ventures, including most startups, lacking the financial resources to pay surcharges.

76. See generally id.

77. With an eye toward providing timely, certain, and flexible enforcement of its open Internet rules, the FCC announced its intention to use advisory opinions similar to those issued by the Department of Justice's Antitrust Division. Id. \ 229, at $* 66$.

Advisory opinions will enable companies to seek guidance on the propriety of certain open Internet practices before implementing them, enabling them to be proactive about compliance and avoid enforcement actions later. The Commission may use advisory opinions to explain how it will evaluate certain types of behavior and the factors that will be considered in determining whether open Internet violations have occurred. Because these opinions will be publicly available, we believe that they will reduce the number of disputes by providing guidance to the industry.

Id. 


\section{CURRENT STRESS POINTS AND DiSPUTES}

Consumers have embraced the Internet in part because it offers faster, better, smarter, cheaper, and more convenient solutions to many ICE wants, needs, and desires. ISPs regularly enhance the value proposition of an Internet-access broadband subscription with network upgrades, offering faster transmission speeds and improvements in the switching and routing of bandwidth-intensive traffic, such as IPTV. As the Internet ecosystem lavishly rewards content and application providers, ISPs appear to have grown increasingly disgruntled with their operating margins and profits relative to the far greater returns accruing to content providers, such as Google and Netflix. From the ISPs' perspective, ventures such as Amazon, eBay, Hulu, and YouTube could not make their business plans work without access to and from ISPs networks. While unable to partner with such ventures, with an eye toward sharing profits, ISPs appear to have undertaken a second-best strategy of increasing their compensation demands for interconnecting with both downstream retail subscribers and upstream users of their networks such as content providers and CDNs.

Retail ISPs in particular have superior leverage in their interconnection and compensation negotiations with other carriers and in their retail-service pricing decisions. The first- and last-mile broadband connection to end users continues to evidence less than robust competition. ${ }^{78}$ End users have a limited number of ISP service options for content uploading and downloading. Typically, the incumbent telephone company provides a DSL and possibly a faster fiber or hybrid fiber/copper option; ${ }^{79}$ the cable television company

78. Tom Wheeler, Chairman, FCC, Prepared Remarks: "The Facts and Future of Broadband Competition" 4 (Sept. 4, 2014), available at https://apps.fcc.gov/edocs_public/attachmatch/DOC-329161A1.pdf("At the low end of throughput, $4 \mathrm{Mbps}$ and $10 \mathrm{Mbps}$, the majority of Americans have a choice of only two providers. That is what economists call a 'duopoly', a marketplace that is typically characterized by less than vibrant competition. But even two 'competitors' overstates the case. Counting the number of choices the consumer has on the day before their Internet service is installed does not measure their competitive alternatives the day after. Once consumers choose a broadband provider, they face high switching costs that include early-termination fees, and equipment rental fees. And, if those disincentives to competition weren't enough, the media is full of stories of consumers' struggles to get ISPs to allow them to drop service."); see also National Broadband Map: How Connected Is My Community?, NAT'L BROADBAND MAP, http://www.broadbandmap.gov/ (last visited Apr. 15, 2015).

79. See, e.g., High Speed Internet, VERIZON, http://www.verizon.com/ home/highspeedinternet/ (last visited Apr. 15, 2015). 
provides a faster and more expensive broadband alternative; ${ }^{80}$ and one or two satellite carriers provide a comparatively more expensive and slower speed delivery option possibly most attractive to rural users lacking other choices. ${ }^{81}$ Terrestrial wireless carriers have begun to offer a competitive option, albeit one typically already imposing content downloading caps that raise the per-megabyte cost of service well above wireline options. Additionally, questions exist about their ability to maintain advertised broadband speeds during peak demand conditions. $^{82}$

Most retail consumers select one and only one carrier to handle all of their Internet traffic requirements. ${ }^{83}$ Should a service disruption occur upstream, almost all ISPs can activate or procure alternative interconnection arrangements quickly. But at the retail sector, even consumers with competitive options will encounter some delay and expense in migrating from one carrier to another.

In light of the possibly limited competitive options available for retail Internet-access subscribers and their sole reliance on one carrier, the chosen ISP has significant negotiating power with both end users and upstream ISPs. End users may balk at the

80. See, e.g., High-Speed Internet Service with XFINITY® Internet from Comcast, COMCAST, http://www.comcast.com/internet-service.html (last visited Apr. 15, 2015).

81. See, e.g., Deals and Pricing, WiLDBLUE, http://www.wildblue.com/ options/availability (last visited Apr. 15, 2015).

82. Hibah Hussain et al., Capping the Nation's Broadband Future? Dwindling Competition Is Fueling the Rise of Increasingly Costly and Restrictive Internet Usage Caps, New AM. Found. (Dec. 17, 2012), http://newamerica.net/ publications/policy/capping_the_nation_s_broadband_future.

[D] ata usage is highly skewed: a small group of very intensive data users tie up the network and degrade service for moderate users, who paid the same price. The arrival of high-quality mobile video turbo-charges this: one high-def TV show is most of a gigabyte, while smartphone users who are voice and text-oriented (like me) are unlikely to consume more than 2$3 \mathrm{~GB} /$ month.

Todd Hixon, Verizon Makes Wireless Pricing Rational, Forbes (Aug. 28, 2012, 8:34 AM), http://www.forbes.com/sites/toddhixon/2012/08/28/verizon-makeswireless-pricing-rational/.

83. Verizon v. FCC, 740 F.3d 623, 646 (D.C. Cir. 2014) ("The Commission also convincingly detailed how broadband providers' position in the market gives them the economic power to restrict edge-provider traffic and charge for the services they furnish edge providers. Because all end users generally access the Internet through a single broadband provider, that provider functions as a 'terminating monopolist' with power to act as a 'gatekeeper with respect to edge providers that might seek to reach its end-user subscribers." (citations omitted)). 
inconvenience of changing carriers, ${ }^{84}$ and upstream ISPs will have no migration option at all if they want to secure access to all end users. Put another way, if a single ISP enjoys a dominant market share of the retail market, which occurs in many localities, a substantial portion of the market exclusively relies on that single ISP making it absolutely necessary for upstream ISPs to secure an agreement with that ISP for its delivery of content. A single ISP has the potential to exert substantial control over access to a majority of the end-user market in many places. ${ }^{85}$ Content providers and distributors are captive to that ISP in the sense that they must secure delivery to the televisions, computer monitors, smartphones, and tablets that access the Internet solely via a single ISP. ${ }^{86}$

\section{A. Internet Protocol Television and OTT Applications Trigger Vast}

Increases in Downstream Traffic

As smartphones and tablets replace less versatile wireless handsets, consumers increasingly will use these devices for accessing broadband IPTV and OTT services. Netflix currently generates as much as $34 \%$ of the total traffic ISPs handle at peak hours, making IPTV one of the primary causes for increasing bandwidth demand and consumers' interest in securing a broadband subscription. ${ }^{87}$ The expansion in downstream traffic has triggered a number of adjustments and ISP demands for additional compensation.

In light of growing demand for bandwidth-intensive, video content delivered via the Internet, traffic-volume disparities have increased between ISPs, particularly between ISPs providing "retail" broadband service to end users and other upstream ISPs such as CDNs. As demand for IPTV services increases, Internet traffic flows

84. "[M]any end users may have no option to switch, or at least face very limited options ...." Id. at 647.

85. See Preserving the Open Internet, 25 FCC Rcd. 17,905, 17,924-25 (2010), aff'd in part, vacated and remanded in part sub nom. Verizon, 740 F.3d 623, on remand Protecting and Promoting the Open Internet, 79 Fed. Reg. 37,448 (Jul. 1, 2014); see also Verizon, 740 F.3d at 646.

86. For a summary of major peering disputes, see Jon Brodkin, Why YouTube Buffers: The Secret Deals That Make-and Break-Online Video, ARS TECHNICA (Jul. 28, 2013， 9:00 PM), http://arstechnica.com/informationtechnology/2013/07/why-youtube-buffers-the-secret-deals-that-make-and-breakonline-video/.

87. Drew Fitzgerald, Netflix's Share of Internet Traffic Grows, Wall St. J. (May 14, 2014, 7:13 PM), http://www.wsj.com/articles/SB100014240527023049 08304579561802483718502 . 
will become even more asymmetrical, necessitating new or additional payments from ISPs and CDNs with growing downstream volume and retail ISPs delivering the traffic to end users. Instead of applying a zero-payment barter model, retail ISPs demand and receive financial compensation. Content distributors, such as Netflix, also consider alternatives to using CDNs, by securing a paid-peering arrangement directly with one or more national ISPs ${ }^{88}$ or installing servers containing the most popular content closer to subscribers. ${ }^{89}$

CDNs typically become transit payers even if previously they qualified for zero-cost peering, but questions remain whether retail ISPs, such as Comcast, have an affirmative duty to try offsetting traffic imbalances. Likewise, consumers wonder what service commitments they deserve to receive from their retail ISPs, which accrue sizeable monthly Internet-access subscription revenues. The carriers respond that they have had to increase available network capacity and thereby enhance the value proposition of service despite not receiving additional compensation from the ventures, causing massive increases in download volume, i.e., ventures such as Netflix and YouTube.

On occasion, retail broadband subscribers have experienced degraded service, particularly for bandwidth-intensive applications such as full-motion video streaming..$^{90}$ Identifying the actual cause of such congestion remains elusive. Content creators and distributors speculate whether retail ISPs have deliberately caused congestion, by refusing to make timely network capacity upgrades or by allocating available capacity in ways that increase the probability of congestion for the traffic of specific content types and sources. ISPs reject this scenario and cite to less nefarious circumstances such as weather, home-based holidays, and the decision of content distributors, such as Netflix, to release an entire season's worth of a program instead of

88. Shalini Ramachandran, Netflix to Pay Comcast for Smoother Streaming, WaLl ST. J. (Feb. 23, 2014, 7:47 PM), http://www.wsj.com/articles/SB1000142 4052702304834704579401071892041790.

89. Content providers and distributors can opt to negotiate directly with retail ISPs for the right to install ("co-locate") equipment on site or alternatively secure the services of a company, such as Akamai, to negotiate, install, and maintain the equipment. Netflix has sought the direct negotiation option with ISPs. Ken Florance, Announcing the Netflix Open Connect Network, NeTflix US \& CAN. Blog (June 4, 2012, 2:48 PM), http://blog.netflix.com/2012/06/announcing-netflix-openconnect-network.html.

90. Fitzgerald \& Ramachandran, supra note 5. 
the conventional weekly release of just one episode. ${ }^{91}$ Consumers and regulators alike have no means for identifying the trigger, because multiple carriers participate in the complete routing of traffic from source to end user. Sophisticated network tracking techniques are needed to identify the network operating the weakest link with the lowest available bandwidth and switching capacity that can cause end users to experience delays in downloads and even dropped packets of content.

\section{B. Increasing Content and Delivery Costs Result in More Interconnection and Compensation Disputes and Creative Solutions}

In lieu of, or in addition to, the use of CDNs, content sources can opt for a direct routing option where they secure a peering arrangement for a price. Such paid peering ${ }^{92}$ provides "most favored nation" treatment of specific traffic streams by routing it via dedicated transmission capacity for most, if not all, of the complete routing. This arrangement provides higher quality of service by reducing - if not eliminating - the use of other networks, thereby expediting delivery of traffic even when congestion would degrade traffic over lines subject to traditional "best efforts" routing. ${ }^{93}$ Under

91. "The hit political drama series of Netflix kept about 60,000 subscribers glued onto their screens on Valentine's Day to watch the whole 13-hour production. However, the shifting behavior of consumers to watch videos on demand over the Internet is causing some clogged pipes on the information highway." Suba, supra note 5 .

92. Yoo, supra note 32, at 95-96 ("Paid peering involves all of the same aspects as conventional peering relationships. Peers announce to the rest of the Internet the addresses that their peering partners control, maintain a sufficient number of interconnection points across the country, and maintain the requisite total volume and traffic ratios. The key difference is that one peering partner pays the other partner for its services.").

93. Alexander Reicher, Note, Redefining Net Neutrality After Comcast v. FCC, 26 Berkeley TeCH. L.J. 733, 752 (2011) ("Paid peering, for example, resembles normal peering in almost every respect, except that one network pays the other network even when the exchange of traffic is roughly the same. These more sophisticated agreements reflect the fact that while the traffic exchange may be equal, the cost of maintaining the networks' respective infrastructures may be unequal. ISPs serving a smaller number of large internet content websites (known as 'content networks') have lower costs in maintaining their infrastructure than ISPs serving home users ('eyeball networks'), since residential neighborhoods require more equipment investment (such as wiring) and maintenance than commercial areas. These interconnection agreements create the economic incentives for ISPs to route internet traffic along the lowest-cost paths, which can sometimes have a 
a paid-peering arrangement, traffic can arrive via the most advantageous means, resulting in less latency, less circuitous routing arrangements, and the use of fewer routers and other switching equipment.

Companies, such as Netflix, have opted to pay for peering rather than risk the consequences of degraded network delivery of "mission critical," bandwidth-intensive video. ${ }^{94}$ The decision by Netflix to secure paid-peering access to the Comcast network triggered extensive commentary and analysis. ${ }^{95}$ Some believe Netflix capitulated to extortion by succumbing to thinly veiled threats by retail ISPs like Comcast that, absent surcharge payments, Netflix video file downloads would regularly trigger congestion and a degraded customer experience. ${ }^{96}$ These observers believe Comcast caused Netflix traffic to slow down as a way to extort a surcharge payment $^{97}$ from high-volume sources of content to help underwrite needed network upgrades. ${ }^{98}$ Others consider paid peering a pragmatic and commercially wise decision by Netflix to secure enhanced quality-of-service delivery guarantees to achieve greater certainty

discriminatory effect on certain types of content, applications, and services." (emphasis omitted) (footnotes omitted)).

94. See Comcast and Netflix Team Up to Provide Customers Excellent User Experience, NetFlix MEdiA Center (Feb. 23, 2014), https://pr.netflix.com/ WebClient/getNewsSummary.do?newsId=992.

95. For a collection of commentaries and critiques, see Headlines Newsletter, BENTON Found., http://benton.org/headlines/newsletter (last visited Apr. $15,2015)$.

96. Joan Engebretson, Verizon, Netflix Dispute Not Just over Peering; Servers Are New Battlefield, TELECOMPETITOR (June 20, 2013, 12:26 PM), http://www.telecompetitor.com/verizon-netflix-dispute-not-just-over-peering-

servers-are-new-battlefield/ ("High-profile flare-ups between content providers and broadband providers over traffic exchange are becoming an annual or even semiannual Internet tradition. The latest flare-up is between Cogent Communications, which provides backbone connectivity for Netflix, and Verizon. But this time there's a new issue embedded in an old issue. The old issue is how to deal with traffic imbalances between broadband providers and content providers who tend to send more traffic to broadband providers than they receive from them. The new issue pertains to a new approach to solving those traffic exchange problems - allowing the content provider to put servers in key broadband provider connection points, thereby minimizing the distance content has to travel between the two companies. The goal is to minimize transport costs and enhance the quality of the end user experience. And the fight now seems to be over who controls those arrangements.").

97. See, e.g., Wu, supra note 21; USA ISP Speed Index Results Graph October 2014-February 2015, NETFLIX, http://ispspeedindex.netflix.com/results/ usa/graph (last visited Apr. 15, 2015); see also Fitzgerald \& Ramachandran, supra note 5 .

98. See, e.g., Crawford, supra note 21. 
that subscribers would not experience degraded service ${ }^{99}$ in light of the real possibility that Netflix traffic could trigger congestion. ${ }^{100}$

The migration from peer to transit, or paid-peering partner, represents one of many adjustments in interconnection compensation arrangements triggered by changes in traffic flows. ${ }^{101}$ Heretofore, commercially driven negotiations have managed the transition without resulting in many service disruptions. However, it appears increasingly likely that interconnection negotiations will become more contentious and protracted, ${ }^{102}$ particularly when retail ISPs demand compensation from sources of high volume, bandwidthintensive video content with which the ISPs do not interconnect directly. As the Internet becomes a more common medium for the delivery of video content, more compensation disputes will arise that have possibly greater potential for consumer inconvenience than carriage disputes between content providers and traditional media outlets, such as satellite and cable television operators.

99. See, e.g., Dan Rayburn, Here's How the Comcast \& Netflix Deal Is Structured, with Data \& Numbers, Streaming Media Blog (Feb. 27, 2014, 12:14 PM), http://blog.streamingmedia.com/2014/02/heres-comcast-netflix-deal-structured -numbers.html.

100. Netflix traffic constitutes as much as $34 \%$ of the total volume carried by retail ISPs during peak hours. Fitzgerald, supra note 87.

101. For background on peering, transit, and new interconnection arrangements, see Dennis Weller \& Bill Woodcock, Internet Traffic Exchange: Market Developments and Policy Challenges, OECD Publishing (Jan. 29, 2013), http://www.oecd-ilibrary.org/docserver/download/5k918gpt130q.pdf?expires=1429 219449\&id=id\&accname $=$ guest $\&$ checksum $=21 \mathrm{E} 7 \mathrm{~F} 441 \mathrm{C} 22517730 \mathrm{~F} 8647 \mathrm{C0E} 4 \mathrm{D} 4 \mathrm{~B}$ 684; see also Anna-Maria Kovacs, Internet PEering And Transit (2012), available at http://www.techpolicyinstitute.org/files/amkinternetpeeringandtransit. pdf; DrPeering.net: Resources to Make Strategic Peering Decisions, supra note 45.

102. Lyons, supra note 1, at 1034 ("By regulating the terms upon which content providers use their networks to reach consumers, broadband providers could manipulate the flow of information in society. For example, Comcast could conceivably block consumer access to websites like www.comcastsucks.org that criticize the company. Perhaps more realistically, Comcast could block or degrade content and applications like Netflix that compete against its other revenuegenerating services. Unlike America Online and other first-generation dial-up Internet access providers, most broadband providers do not specialize in providing Internet access alone. Rather, the largest broadband providers are cable and telephone companies, which have incentives to prevent customers from using their broadband connections in ways that threaten their other revenue streams. For example, consumer groups have expressed concerns that broadband Internet providers that also offer on-demand movie rentals via cable might discriminate against other services (such as Netflix or BitTorrent) that make movies available over a broadband connection." (footnotes omitted)). 


\section{Scope and Timetable for FCC Remedies Under $\S 706$ of the Communications Act}

Section 706(a) of the Communications Act requires the FCC and state public utility commissions (PUCs) to "encourage the deployment on a reasonable and timely basis of advanced telecommunications capability to all Americans." ${ }^{103}$ Section 706(b) requires the Commission to conduct an annual inquiry "concerning the availability of advanced telecommunications capability," and, if it determines that access is not available on "a reasonable and timely fashion," to "take immediate action to accelerate deployment of such capability by removing barriers to infrastructure investment and by promoting competition in the telecommunications market." 104 Collectively, § 706 requires an ongoing assessment of whether the broadband ecosystem operates with sufficient competition and accessibility with the FCC obligated to remedy market failure resulting from insufficient infrastructure investment.

The FCC has generated significant opposition to both its determination of inadequate broadband access and its decision to impose open Internet rules as a way to improve access and achieve the goals in $\S$ 706. An assessment of Internet access lacks the simplicity of previous market evaluations undertaken by the Commission and state PUCs. For example, these agencies can readily track progress in conventional voice telephone-service access by compiling statistics about the number of lines per 100 residents in specific geographical areas. Upon determining that inadequate "teledensity" exists, state and federal agencies can promote subscribership by subsidizing rates paid by groups identified as underserved or unable to afford service. Additionally, subsidies can flow directly to carriers to defray the costs of installing Plain Old Telephone Service (POTS) infrastructure into unserved or underserved hinterland locations. ${ }^{105}$

The implementation of $\S 706$ has become even more controversial because the FCC initially had determined that this part of the Communications Act did not confer regulatory authority, ${ }^{106}$

103. 47 U.S.C. $\S 1302(a)(2012)$.

104. Id. § 1302(b).

105. See Universal Service Support Mechanisms, FCC (Oct. 8, 2014), $\mathrm{http} / / /$ www.fcc.gov/guides/universal-service-support-mechanisms.

106. "[W]e conclude that, in light of the statutory language, the framework of the 1996 Act, its legislative history, and Congress' policy objectives, the most logical statutory interpretation is that section 706 does not constitute an independent 
and even if it had, the Commission initially determined that adequate broadband access existed. ${ }^{107}$ The FCC subsequently reversed itself on both grounds. Now in its 2014 Open Internet Order, the FCC has invoked $\S 706$ as requiring it to undertake affirmative efforts to promote Internet access, including rules requiring transparency and disclosure of specialized service arrangements, as well as a prohibition on unreasonable discrimination and blocking lawful content.

The D.C. Circuit Court of Appeals determined that the FCC could reasonably reinterpret $\S 706$ as providing statutory authority for some degree of private carrier oversight: "Does the Commission's current understanding of section 706(a) as a grant of regulatory authority represent a reasonable interpretation of an ambiguous statute? We believe it does." 108

Having determined that it has a foundation for regulatory authority, the FCC has identified inadequacy in broadband access and has restarted the process for determining what strategies to pursue that will create incentives for more investment in broadband

grant of [regulatory] authority." Deployment of Wireline Servs. Offering Advanced Telecomms. Capability, 13 FCC Rcd. 24,012, 24,047 (1998). The FCC subsequently changed its mind and unsuccessfully asserted that $\S 706$ granted it ancillary jurisdiction to regulate information services. The D.C. Circuit Court of Appeals rejected this reading but agreed with a third interpretation that $\S 706$ does provide some basis for non-common carrier oversight.

Setting forth those "reasons" at some length, the Commission analyzed the statute's text, its legislative history, and the resultant scope of the Commission's authority, concluding that each of these considerations supports the view that section 706(a) constitutes an affirmative grant of regulatory authority. In these circumstances, and contrary to Verizon's contentions, we have no basis for saying that the Commission "casually ignored prior policies and interpretations or otherwise failed to provide a reasoned explanation" for its changed interpretation.

Verizon v. FCC, 740 F.3d 623, 637 (D.C. Cir. 2014) (citation omitted).

107. Verizon, 740 F.3d at 640 ("Until shortly before the Commission issued the Open Internet Order, it had never considered whether the provision vested it with any regulatory authority. The Commission had no need to do so because prior to that time it had made no determination that advanced telecommunications technologies, including broadband Internet access, were not 'being deployed to all Americans in a reasonable and timely fashion,' the prerequisite for any purported invocation of authority to 'take immediate action to accelerate deployment of such capability' under section 706(b). In July 2010, however, the Commission concluded that 'broadband deployment to all Americans is not reasonable and timely.' This conclusion, the Commission recognized, represented a deviation from its five prior assessments." (citations omitted)).

108. Id. at 637. 
infrastructure particularly in locales where Internet access lags. ${ }^{109}$ Assessing the adequacy of broadband access, even using broadbandmarket penetration statistics, is anything but straightforward and uncontroversial. Stakeholders disagree on what benchmarks would constitute success and more broadly whether evaluative criteria should change over time. For example, the FCC's National Broadband Plan has articulated a goal for 100 million households to have access to actual (not advertised) speeds of 100 megabits per second (mbps) by the year 2020 with all households having at least 4 mbps downstream and 1 mbps upstream. ${ }^{110}$ Would achieving that goal on or before 2020 trigger the dismantling of any and all supplyside and demand-side promotions and subsidies? More fundamentally, should $\S 706$ success be assessed using national market penetration statistics, or should more narrow targets be used?

Assessing the adequacy of broadband access arguably requires more than the simple compilation of statistics on broadband-line subscribership and available bit-transmission speeds. Consumers' definition of what constitutes basic and adequate broadband service is constantly changing in light of their ever-increasing expectations and service demands. In many households, multiple users may attempt to download full-motion video content at the same time thereby increasing the overall demand for content bit-transmission speed that ISPs must now satisfy. While the FCC has vastly

109. See Preserving the Open Internet, 25 FCC Rcd. 17,905, 17,968 (2010) ("Section 706 of the 1996 Act directs the Commission (along with state commissions) to take actions that encourage the deployment of 'advanced telecommunications capability.' '[A]dvanced telecommunications capability,' as defined in the statute, includes broadband Internet access. Under Section 706(a), the Commission must encourage the deployment of such capability by 'utilizing, in a manner consistent with the public interest, convenience, and necessity,' various tools including 'measures that promote competition in the local telecommunications market, or other regulating methods that remove barriers to infrastructure investment.' For the reasons stated in Parts II.A, II.D and III.B, above, our open Internet rules will have precisely that effect." (footnotes omitted)), aff'd in part, vacated and remanded in part sub nom. Verizon, 740 F.3d 623, on remand Protecting and Promoting the Open Internet, 79 Fed. Reg. 37,448 (Jul. 1, 2014).

110. Chapter 2: Goals for a High Performance America, NAT'L BROADBAND PLAN, http://www.broadband.gov/plan/2-goals-for-a-high-performance-america/ (last visited Apr. 15, 2015). Additionally, "[e]very American community should have affordable access to at least 1 gigabit per second broadband service to anchor institutions such as schools, hospitals and government buildings." Id. The Plan proposes an interim goal of having 100 million U.S. homes with affordable access to actual download speeds of $50 \mathrm{mbps}$ and actual upload speeds of $20 \mathrm{mbps}$. Executive Summary, NAT'L BROADBAND PlAN, http:/www.broadband.gov/plan/executivesummary/ (last visited Apr. 15, 2015). 
improved its reports on available bit-transmission speeds, it still largely ignores qualitative factors that arguably should constitute an integral part of the $\S 706$ evaluation process. For example, the Commission gladly notes the availability of terrestrial and satellite wireless options without considering the impact of data caps, initial equipment costs, cost per megabyte, etc. However, most current subscribers of wireless broadband services have caps on their monthly data usage rarely exceeding a few gigabytes. ${ }^{111}$ In contrast, wireline broadband carrier options either have no cap at all or reference a 250-gigabyte cap without enforcing it. ${ }^{112}$ Wireless subscribers exceeding their data cap face significant surcharges.

If the FCC were to undertake an "apples to apples" measurement of downloading costs for currently offered wireless versus wireline broadband service, it would identify a substantial difference in per-megabyte costs. Such a normalized comparison also would have to factor higher initial equipment costs for wireless services. Most smartphones now exceed the cost of desktop computers. Satellite broadband subscribers typically have to pay several hundred dollars for signal transmission, reception, and processing. ${ }^{113}$ Federal and state regulatory agencies do not typically undertake a calculation of actual out-of-pocket costs incurred by subscribers. Such a calculation would identify substantial cost differentials in services that regulatory agencies all too often consider functional equivalents and direct competitors.

Stakeholders also disagree on whether the FCC would engage in "mission creep" if it were to change benchmarks for determining the adequacy of national broadband penetration, ${ }^{114}$ or if it established new goals for specific locales, such as rural areas and other locales

111. See, e.g., The MORE Everything Plan, VERIzON Wireless, http://www.verizonwireless.com/wcms/consumer/shop/shop-data-plans/moreeverything.html\#configurator (last visited Apr. 15, 2015).

112. See, e.g., High-Speed Internet Service with XFINITY ${ }^{\circledR}$ Internet from Comcast, supra note 80.

113. See, e.g., Deals and Pricing, supra note 81.

114. The FCC has proposed to increase the baseline level of broadband service that satisfies the definition of advanced telecommunications capability. Inquiry Concerning the Deployment of Advanced Telecommunications Capability to All Americans in a Reasonable and Timely Fashion, and Possible Steps to Accelerate Such Deployment Pursuant to Section 706 of the Telecommunications Act of 1996, as Amended by the Broadband Data Improvement Act, 30 FCC Rcd. 1375, I 3, at 1377 (2015). The Commission now proposes a threshold of actual download speed of twenty-five megabits per second and actual upload speed of three megabits per second. Id. 
where more residents have incomes at or below the poverty line than the national average. State and federal regulators may deem it appropriate to raise the bar on what constitutes success as new applications become available, particularly ones that require ever more bandwidth and bit-transmission speed, such as IPTV. Consumers have less patience for "appointment television" that rations access and specifies the time, medium, and screen. Many now expect "on demand" access to any and all video content from up to four screens: the television set, computer monitor, smartphone, and tablet. In the not-too-distant future, they will expect broadband carriers to provide a conduit sufficiently robust to carry highdefinition television as well as new "ultra" high-definition content that doubles both the columns and lines of picture resolution. ${ }^{115}$

\section{New Disruptors}

The evolving Internet ecosystem also encourages new strategies for linking consumers with content outside of traditional peering and transit arrangements. Many new consumers' self-help strategies have evolved, some of which violate the intellectual property rights of content creators and distributors. Additionally, new ventures have devised strategies for delivering content via the Internet in ways that attempt to evade licensing and other forms of payment. While many contact, access, and delivery tactics use questionable or illegal tactics, collectively they have the potential to disrupt, but not necessarily destroy, existing models for content delivery.

Previous disruptors support this premise. For example, cable television initially caused great anxiety among both broadcasters and movie theater operators based on the assumption that this new technology would cause financial havoc by fragmenting audiences and siphoning off revenues. ${ }^{116}$ Rather than trigger a major migration

115. FCC, FCC Chairman Tom Wheeler: More Competition NeEded in High-SpeEd Broadband MARKetPlace 1 (2014), available at https://apps.fcc.gov/ edocs_public/attachmatch/DOC-329160A1.pdf ("By most calculations, a single HD movie requires $5 \mathrm{Mbps}$ and super HD requires $7 \mathrm{Mbps}$ of download speed. The average U.S. Internet-connected homes have six connected devices-televisions, desktops, laptops, tablets, smartphones, etc. When those devices are in use at the same time, it's not difficult to strain the capacity of a $25 \mathrm{Mbps}$ connection, and completely overwhelm a 4 Mbps connection.").

116. See, e.g., Patrick R. Parsons, Blue Skies: A History of Cable TELEVISION 355, 489, 622 (2008) (providing a comprehensive history of cable television development). 
among existing consumers, this new technology expanded the market for audio-visual content. ${ }^{117}$ Additionally, broadcasters considered cable television-carriage piracy, based on the ability to retransmit signals without having to compensate broadcasters for the privilege. Eventually, legislation ${ }^{118}$ preempted a developing body of case law supporting free carriage, ${ }^{119}$ eventually leading to the mutually beneficial relationship between a larger set of MVPDs and broadcasters. Rather than siphon audiences and revenues, MVPDs now compensate most broadcasters while also situating themselves as well-compensated intermediaries between broadcasters and consumers. Approximately $90 \%$ of all households with television sets receive video content via an MVPD instead of directly off air. ${ }^{120}$

\section{Aereo and Questions About Cloud-Based Content Access}

Comcast's demand for increased compensation from Netflix and its CDNs raises broader questions about how various stakeholders will fare in future commercial negotiations for access to content and for carriage. The possibility exists that content creators and distributors will attempt to eliminate intermediaries who receive compensation for functions that can be replaced or eliminated. MVPDs in particular appear at risk for such disintermediation because the Internet can match or exceed their content-delivery performance and replicate their ability to aggregate, bill, and collect payment from a sizeable audience. ${ }^{121}$

117. See id. at 578,586 .

118. Cable Communications Policy Act of 1984, Pub. L. 98-549, 98 Stat. 2779 (codified as amended in scattered sections of 47 U.S.C.).

119. See, e.g., Teleprompter Corp. v. Columbia Broad. Sys., Inc., 415 U.S. 394, 405 (1974) (holding that there was no copyright infringement for retransmission of distant broadcast television signals); Fortnightly Corp. v. United Artists Television, Inc., 392 U.S. 390, 400-02 (1968) (holding that a community antenna television system retransmission of unaltered broadcast signal did not constitute a public performance and copyright infringement).

120. Annual Assessment of the Status of Competition in the Mkt. for the Delivery of Video Programming, 28 FCC Rcd. 10,496, 10,500 (2013) (Fifteenth Report) ("Since the last report, the number of households relying exclusively on over-the-air broadcast service has remained steady at approximately 11.1 million households, although the percentage of all households they represent increased slightly from 9.6 percent in 2011 to 9.7 percent in 2012.").

121. For example, Dish Network recently announced a satellite or Internet delivery service comprised of twelve cable networks for $\$ 20$ a month, a rate well below the average monthly cable or DBS rate. Emily Steel, Dish Network Unveils 
The tactics and accomplishments of illegal and legally suspect disintermediation options can provide insight of what lawful tactics may soon appear. For example, downloading video files using peerto-peer software, such as that provided by BitTorent, initially provided a faster way to share mostly pirated content. ${ }^{122}$ Over time, carriers and content providers alike have considered this file-sharing technique as an efficient and speedy content delivery option. ${ }^{123}$

The unsuccessful legal campaign of Aereo may follow a similar track from unlawful piracy to legitimacy, at least for the underlying technology used. Aereo devised a technical and legal strategy aiming to use the Internet to deliver broadcast television signals without compensating copyright holders. ${ }^{124}$ Relying on Cartoon Network LP v. CSC Holdings, Inc. ${ }^{125}$ the company devised a strategy that attempted to emphasize end-user control over signal reception and delivery, instead of the retransmission of copyrighted content without authorization.

The Second Circuit Court of Appeals held that a cable television operator, Cablevision, did not infringe on the copyrights of networks carried by the company when it made an individual copy of copyrighted video content on behalf of a specific subscriber. ${ }^{126}$

Sling TV, a Streaming Service to Rival Cable (and It Has ESPN), N.Y. TIMES, Jan. 6,2015 , at B3.

122. Amy Rosen, The Big Lawsuits Keep on Coming: An Analysis of Extortive Pornographic "Trolling Lawsuits" and Preventative Approaches, ENT. \& SPORTS LAw. Mar. 2014, at 1, 21-22 ("The P2P system works by using the Internet to connect computer systems to each other, with files directly shared between systems on the network without the need of a central server. . . . The BitTorrent system is a type of P2P network, but reduces the bandwidth required to transfer files. The BitTorrent system finds many computers that each send pieces of a broken file to the downloading computer. After receiving the smaller pieces of the file from multiple computers, the BitTorrent program puts the file pieces back together to recreate the original file. The BitTorrent system is more efficient than the regular P2P system because it relies on multiple computers for smaller pieces, instead of one computer for an entire file." (footnotes omitted)); see Peter $\mathrm{K}$. Yu, P2P and the Future of Private Copying, 76 U. CoLO. L. REV. 653, 695-96, 742 (2005) (providing background and a historical context that demonstrates technological progress).

123. Betsy Isaacson, BitTorrent Wants You to Know It's a Legitimate Business, HufFington Post (Feb. 17, 2014, 10:59 AM), http://www.huffingtonpost.com/2014/02/17/bitorrent-piracy_n_4781654.html.

124. See Am. Broad. Cos. v. Aereo, Inc. (Aereo), 134 S. Ct. 2498, 2503 (2014).

125. 536 F.3d 121 (2d Cir. 2008).

126. Id. at 131, 135, 139 ("There are only two instances of volitional conduct in this case: Cablevision's conduct in designing, housing, and maintaining a system that exists only to produce a copy, and a customer's conduct in ordering that system 
Responding to commands from subscribers to record content did not constitute the unauthorized transmission of such content-an integral part of the proof needed to evidence a public performance in turn direct liability for copyright infringement.

The Cablevision remote-storage function divided into two parts. ${ }^{127}$ First, Cablevision routinely, but temporarily, buffered video content so that it could make copies as directed by subscribers. The court deemed the buffering function transitory and not sufficiently fixed to constitute a copy. ${ }^{128}$ Cablevision also converted the buffered content into a fixed copy as directed by individual subscribers. The court held that such "playback" copies did constitute unauthorized copies but determined that the copying party was not Cablevision but in fact were individual subscribers who directed Cablevision equipment to make the copies. ${ }^{129}$ Because the plaintiffs in the case did not seek to prove secondarily liability on the part of Cablevision for facilitating and inducing the copies, the company incurred no liability for its remote DVR service. ${ }^{130}$

The court also determined that cable television subscribers directing the company to make copies also did not directly infringe

to produce a copy of a specific program. In the case of a VCR, it seems clear-and we know of no case holding otherwise - that the operator of the VCR, the person who actually presses the button to make the recording, supplies the necessary element of volition, not the person who manufactures, maintains, or, if distinct from the operator, owns the machine. We do not believe that an RS-DVR customer is sufficiently distinguishable from a VCR user to impose liability as a direct infringer on a different party for copies that are made automatically upon that customer's command.").

127. Id. at 124 ("Under the new RS-DVR, this single stream of data is split into two streams. The first is routed immediately to customers as before. The second stream flows into a device called the Broadband Media Router ('BMR'), which buffers the data stream, reformats it, and sends it to the 'Arroyo Server,' which consists, in relevant part, of two data buffers and a number of high-capacity hard disks. The entire stream of data moves to the first buffer (the 'primary ingest buffer'), at which point the server automatically inquires as to whether any customers want to record any of that programming. If a customer has requested a particular program, the data for that program move from the primary buffer into a secondary buffer, and then onto a portion of one of the hard disks allocated to that customer." (citation omitted) (citing Twentieth Century Fox Film Corp. v. Cablevision Sys. Corp., 478 F. Supp. 2d 607, 613 (S.D.N.Y. 2007))).

128. Id. at 127-30.

129. Id. at 131-33.

130. Id. at 137 ("[B]ecause the RS-DVR system, as designed, only makes transmissions to one subscriber using a copy made by that subscriber, we believe that the universe of people capable of receiving an RS-DVR transmission is the single subscriber whose self-made copy is used to create that transmission."). 
the copyright of the content creators. Whether by using a DVR at home or a remote DVR on the premises of the cable company, the subscriber secures a copy of content he or she already has a right to consume. ${ }^{131}$

The Supreme Court eventually decided that Cartoon Network precedent should not apply to Aereo because the company operated much like a cable television service whose retransmission of copyrighted material constitutes a public performance requiring broadcaster consent. ${ }^{132}$ Aereo had attempted to avoid this classification by claiming that it merely installed a small antenna for each and every subscriber so that they individually could direct the company to deliver via the Internet the received broadcast signal and also to make copies for later delivery.

Writing for the majority, Justice Breyer distilled the case into two questions: "First, in operating in the manner described above, does Aereo 'perform' at all? And second, if so, does Aereo do so 'publicly?"'133 The majority decision answers both questions in the affirmative. Aereo performs because its broadcast signal retransmission and copying function parallels the functions of a cable television venture and satisfies the definition of performance enacted by Congress in the 1976 amendment of the Copyright Act. ${ }^{134}$

Referring to the legislative history of the 1976 amendment, Justice Breyer reports that Congress consciously sought to reverse two Supreme Court decisions that considered the cable television retransmission function not a public performance. In Fortnightly Corp. v. United Artists Television, Inc., the Court held that a community antenna television (CATV) system did not publicly perform copyrighted broadcast television content when it simply distributed it to subscribers without alteration in much the same way that individuals could have done using their own antennas. ${ }^{135}$ In Teleprompter Corp. v. Columbia Broadcasting System, Inc., the Court considered the copyright liability of a CATV provider that delivered broadcast television programming from distant sources that

131. Id. at 139 ("Because each RS-DVR playback transmission is made to a single subscriber using a single unique copy produced by that subscriber, we conclude that such transmissions are not performances 'to the public,' and therefore do not infringe any exclusive right of public performance.").

132. Aereo, 134 S. Ct. 2498, 2504-05, 2507-10 (2014).

133. Id. at 2504 .

134. 17 U.S.C. $\$ 101$ (2012).

135. 392 U.S. 390, 400-01 (1968). 
subscribers could not receive if they had erected a rooftop antenna. ${ }^{136}$ The Court had reasoned that cable operators functioned like a private viewer and not a broadcaster or performer. ${ }^{137}$ Justice Breyer reasoned that because Congress expressly created language deeming content transmission a public performance, the Court had to treat Aereo's delivery service as the functional equivalent of a transmission and public performance, notwithstanding the fact that subscribers initiate the transmission and copying functions performed by the company: "This history makes clear that Aereo is not simply an equipment provider. Rather, Aereo, and not just its subscribers, 'perform[s]' (or 'transmit[s]'). Aereo's activities are substantially similar to those of the CATV companies that Congress amended the Act to reach." $" 138$

The majority decision rejects as insignificant a difference in the manner by which copyrighted content reaches subscribers. ${ }^{139}$ Cable retransmission occurs simultaneously and continuously without authorization or direction from subscribers while Aereo requires subscribers to initiate the service and determine whether to direct equipment to make copies. Writing in dissent, Justice Scalia considers this difference significant because the transmission and copying function does not occur unless and until a subscriber directs Aereo equipment to activate. ${ }^{140}$ Justice Scalia analogized the coordination between Aereo and its subscribers to that which occurs when a copy center issues an equipment activation and library card

136. 415 U.S. 394, 399-401 (1974).

137. "Although the Court recognized that a viewer might not be able to afford amplifying equipment that would provide access to those distant signals, it nonetheless found that the CATV provider was more like a viewer than a broadcaster." Aereo, 134 S. Ct. at 2505 (citing Teleprompter, 415 U.S. at 408-09).

138. Id. at 2506 (alterations in original); see also id. at 2506-07 ("Aereo's equipment may serve a 'viewer function'; it may enhance the viewer's ability to receive a broadcaster's programs. It may even emulate equipment a viewer could use at home. But the same was true of the equipment that was before the Court, and ultimately before Congress, in Fortnightly and Teleprompter.").

139. "Given Aereo's overwhelming likeness to the cable companies targeted by the 1976 amendments, this sole technological difference between Aereo and traditional cable companies does not make a critical difference here." Id. at 2507.

140. Id. at 2514 (Scalia, J., dissenting) ("Rather, it assigns each subscriber an antenna that - like a library card — can be used to obtain whatever broadcasts are freely available. Some of those broadcasts are copyrighted; others are in the public domain. The key point is that subscribers call all the shots: Aereo's automated system does not relay any program, copyrighted or not, until a subscriber selects the program and tells Aereo to relay it."). 
for customers who make copies on their own volition, using the copy center's equipment. ${ }^{141}$

On the issue of whether Aereo publicly performs copyrighted material, the majority determined that the company did publicly perform despite having installed a dedicated antenna for the exclusive use of one subscriber. ${ }^{142}$ Even if the Court were to accept the view that Aereo initiated a new performance in its reception and retransmission function, the majority still considered the performance public. $^{143}$ Justice Breyer reasoned that Congress intended on protecting broadcasters' copyrights even if technological innovations involved subscriber interaction with equipment and content streams did not flow instantaneously and constantly to subscribers:

[W] hy should any of these technological differences matter? They concern the behind-the-scenes way in which Aereo delivers television programming to its viewers' screens. They do not render Aereo's commercial objective any different from that of cable companies. Nor do they significantly alter the viewing experience of Aereo's subscribers. Why would a subscriber who wishes to watch a television show care much whether images and sounds are delivered to his screen via a large multisubscriber antenna or one small dedicated antenna, whether they arrive instantaneously or after a few seconds' delay, or whether they are transmitted directly or after a personal copy is made? And why, if Aereo is right, could not modern CATV systems simply continue the same commercial and consumer-oriented activities, free of copyright restrictions, provided they substitute such new technologies for old?

141. Id. at 2513 ("A comparison between copy shops and video-on-demand services illustrates the point. A copy shop rents out photocopiers on a per-use basis. One customer might copy his 10-year-old's drawings - a perfectly lawful thing to do-while another might duplicate a famous artist's copyrighted photographs - a use clearly prohibited by $\S 106(1)$. Either way, the customer chooses the content and activates the copying function; the photocopier does nothing except in response to the customer's commands. Because the shop plays no role in selecting the content, it cannot be held directly liable when a customer makes an infringing copy."). "Aereo does not 'perform' for the sole and simple reason that it does not make the choice of content. And because Aereo does not perform, it cannot be held directly liable for infringing the Networks' public-performance right." Id. at 2514.

142. Id. at 2507 (majority opinion).

143. Id. at 2508 ("When an Aereo subscriber selects a program to watch, Aereo streams the program over the Internet to that subscriber. Aereo thereby 'communicate[s]' to the subscriber, by means of a 'device or process,' the work's images and sounds. And those images and sounds are contemporaneously visible and audible on the subscriber's computer (or other Internet-connected device). So under our assumed definition, Aereo transmits a performance whenever its subscribers watch a program." (citation omitted)). 
Congress would as much have intended to protect a copyright holder from the unlicensed activities of Aereo as from those of cable companies. ${ }^{144}$

The majority opinion interprets the Transmit Clause contained in the 1976 Copyright Act amendments ${ }^{145}$ as applicable regardless of whether there are multiple, geographically diverse, discrete, timedelayed, or subscriber-initiated transmissions from Aereo equipment. ${ }^{146}$ While sensitive to the possibility that its decision at least temporarily blocks technological and entrepreneurial innovations, the Court suggests that Congress can and will act, just as it did in response to the onset of cable television.

The Court also recognized that fair use may allow some innovations to flourish and also seeks to exempt the decision from related questions about Internet-based, "cloud" storage of content. ${ }^{147}$ However, having rejected Aereo's legal interpretation and having nullified the Cartoon Network case, the Court raises the question about what new ventures can do to facilitate consumer storage, sharing, and transmission of video content. While not directly addressing network neutrality, the Aereo case raises questions about whether and how IPTV and OTT applications can replace traditional content-distribution technologies. The Aereo case may have an adverse impact on venture capitalists' enthusiasm for funding new ventures with business plans that rely on nondiscriminatory access to broadband networks and the Internet cloud for storage and delivery of content.

144. Id. at 2508-09.

145. 17 U.S.C. $§ 101$ (2012).

146. "Therefore, in light of the purpose and text of the Clause, we conclude that when an entity communicates the same contemporaneously perceptible images and sounds to multiple people, it transmits a performance to them regardless of the number of discrete communications it makes." Aereo, 134 S. Ct. at 2509. "So whether Aereo transmits from the same or separate copies, it performs the same work; it shows the same images and makes audible the same sounds. Therefore, when Aereo streams the same television program to multiple subscribers, it 'transmit[s] . . a performance' to all of them." Id.

147. The Internet cloud refers to the vast array of interconnected networks that make up the Internet and provide users with seamless connectivity to these networks and the content available via these networks: "The increasing functionality of the Internet is decreasing the role of the personal computer. This shift is being led by the growth of 'cloud computing' - the ability to run applications and store data on a service provider's computers over the Internet, rather than on a person's desktop computer." Robison, supra note 10, at 1199 (footnote omitted); see also Jake Vandelist, Note, Status Update: Adapting the Stored Communications Act to a Modern World, 98 MinN. L. REv. 1536, 1545-46 (2014). 


\section{Other Types of Disintermediation}

Another form of disintermediation combines broadband delivery of "must see" content packaged by incumbents themselves and delivered to individual consumers without the assistance of intermediaries, such as MVPDs. Major sources of quite desirable content, including ESPN, Major League Baseball, the National Football League Network, and HBO have experimented with premium-content delivery options directly via the Internet. ${ }^{148}$

Major content providers have acted with caution in assessing options for disintermediating cable and satellite television operators. MVPDs continue to offer a large bundle of channels in a programming tier, without an option for subscribers to select networks on an a la carte basis. Heretofore, content creators and packagers have determined that the cost of having to share revenues with MVPDs is less than the upside gain in offering their content directly to consumers. By having their content bundled in a basic or enhanced-basic tier to which most consumers subscribe, content producers receive a smaller per-subscriber payment but higher total revenues in light of the number of subscribers paying for access to the programming tier. For example, ESPN receives approximately $\$ 5.54$ per subscriber per month from MVPDs $^{149}$ who include this network in a programming tier paid for by just about every

148. Brian Moylan, HBO Go Without Needing Cable? Welcome to the Future of Television, GUARDIAN (Sept. 13, 2013, 8:00 AM), http:// www.theguardian.com/media/2014/sep/13/hbo-go-without-needing-cable-welcometo-the-future-of-television ("The talk these days in cable television is all about "cord cutters', those people who are willing to get their TV fix by watching shows on a channel's website, downloading them from iTunes, or even waiting for them to show up on streaming services like Netflix and Hulu and then binging every episode at once. HBO Go is the cord cutter's holy grail. It allows HBO subscribers access to all of HBO's movies and original programs, on demand. Now it looks like HBO Go might be available to those without cable. Welcome to the future."); see also Mark Rogowsky, Cut the Cord? HBO Considers Selling Direct to Better Combat Netflix, FORBES (Sept. 11, 2014, 5:15 AM), http:/www.forbes.com/sites/ markrogowsky/2014/09/11/capocalypse-now-hbo-edges-closer-to-blowing-up-thecable-industry-as-we-know-it/; Mark Rogowsky, Is It Time for HBO to Sell Directly to Consumers?, ForBes (Oct. 22, 2013, 11:53 AM), http://www.forbes.com/ sites/markrogowsky/2013/10/22/with-netflix-rolling-is-it-time-for-hbo-to-go-direct/.

149. The media research firm SNL Kagen reports that ESPN charges MVPDs approximately $\$ 5.54$ per month per subscriber, a rate four times the monthly fee for the next most expensive national network. Richard Sandomir, James Andrew Miller \& Steve Eder, To Protect Its Empire, ESPN Stays on Offense, N.Y. TIMES, Aug. 27, 2013, at A1. 
subscriber. Even if ESPN could double or triple the per-subscriber charge if it were to make its content available on an a la carte basis via an MVPD network, or even independently via the Internet, the company's total gross revenues apparently would fall.

MVPD bundling of many channels forces subscribers to pay for content they do not desire. Faced with rising content costs, MVPDs offering large bundles of content have to increase monthly subscription rates, typically well in excess of general measures of inflation. ${ }^{150} \mathrm{~A}$ small but growing number of subscribers have "cut the cord" and abandoned their MVPD subscription based on such rising costs and the assumption that they can access enough "must see" content from IPTV and other on-demand sources such as Netflix and Hulu. ${ }^{151}$ Should this customer churn grow, MVPDs might have to offer lower cost a la carte content-selection options even though this also might improve the financial payoff from their disintermediation by major content creators.

So far, MVPDs and content creators have closed ranks and attempted to enhance the value proposition of the status quo. Many MVPD now offer subscribers opportunities to access prime content on demand using IPTV and OTT applications that deliver the content to multiple screens, including mobile smartphone handsets and tablets. Going forward, it appears that consumers will have more options for accessing premium content for pay but without compulsory additional subscription payments to an MVPD.

150. Implementation of Section 3 of the Cable Television Consumer Prot. \& Competition Act of 1992, 29 FCC Rcd. 14,895, 14,895 (2014) ("The average monthly price of expanded basic service (the combined price of basic service and the most subscribed cable programming service tier excluding taxes, fees and equipment charges) for all communities surveyed increased by 3.1 percent over the 12 months ending January 1, 2014, to \$66.61, compared to an annual increase of 1.6 percent in the Consumer Price Index (CPI). The price of expanded basic service has increased at a compound average annual growth rate of 5.9 percent during the period 1995-2014. The CPI increased at a compound average annual growth rate of 2.4 percent over the same period.").

151. Edmund Lee, TV Subscriptions Fall for First Time as Viewers Cut the Cord, BloombergBusiness (Mar. 19, 2014, 2:38 PM), http://www. bloomberg.com/news/2014-03-19/u-s-pay-tv-subscriptions-fall-for-first-time-asstreaming-gains.html ("The number of Americans who pay for TV through cable, satellite or fiber services fell by more than a quarter of a million in 2013, the first full-year decline, according to research firm SNL Kagan. If the slide continues in the coming years, that means 2012 was the industry's high point."). 


\section{IS THERE A WAY FORWARD?}

The network neutrality debate continues to present the FCC and other National Regulatory Authorities (NRAs) with seemingly unresolvable challenges. They have to address macro-level issues such as whether and how to remedy limitations on marketplace selfregulation even as technological innovations and other changed circumstances require a modification of current policies. Regulatory agencies appear neither able to respond to technological and marketplace changes in a timely manner nor can legislatures craft laws that can work effectively well past the year of enactment.

The Internet ecosystem has proven quite vibrant and able to work well with limited but essential government oversight. The key lies in how well the FCC and other NRAs can calibrate their oversight and marketplace intervention to the minimal degree necessary. This process requires great finesse and the willingness to abandon absolute and unmovable positions based on political and economic doctrines.

As a starting point for considering the way forward, perhaps it makes sense to look back to a time when all five FCC Commissioners agreed on a baseline Internet policy. In 2005, the FCC released a short Policy Statement identifying four principle values the Commission should embrace. ${ }^{152}$ The Commission reached bipartisan agreement:

To encourage broadband deployment and preserve and promote the open and interconnected nature of the public Internet, consumers are entitled to access the lawful Internet content of their choice.

To encourage broadband deployment and preserve and promote the open and interconnected nature of the public Internet, consumers are entitled to run applications and use services of their choice, subject to the needs of law enforcement.

To encourage broadband deployment and preserve and promote the open and interconnected nature of the public Internet, consumers are entitled to connect their choice of legal devices that do not harm the network.

To encourage broadband deployment and preserve and promote the open and interconnected nature of the public Internet, consumers are entitled to competition among network providers, application and service providers, and content providers. ${ }^{153}$

152. Appropriate Framework for Broadband Access to the Internet over Wireline Facilities, 20 FCC Rcd. 14,986, 14,988 (2005).

153. Id. (emphasis omitted) (footnote omitted). 
In these hyper partisan and contentious times, one can have great skepticism whether a unanimous FCC could agree on these principles, even though they do not operate as binding rules and have no enforceability. Yet, these principles remain as essential now as they did in 2005. Nothing has so changed in terms of technological and marketplace development to reduce the need for a limited FCC role to prevent subversion of these principles. 